\title{
Different Climatic Effects of the Arctic and Antarctic ice Covers on Land Surface Temperature in the Northern Hemisphere: Application of Liang- Kleeman Information Flow Method and CAM4.0
}

\section{Shunyu Jiang}

Nanjing University

Haibo HU ( $\sim$ huhaibo@nju.edu.cn )

Nanjing University https://orcid.org/0000-0003-1457-9538

William Perrie

Bedford Institute of Oceanography

Ning Zhang

Nanjing University

Haokun Bai

Nanjing University

Yihang Zhao

Nanjing University

\section{Research Article}

Keywords: The Liang-Kleeman information flow, trans-equatorial climate effect, atmospheric waveactivity flux, configuration of ice cover and jet stream

Posted Date: May 3rd, 2021

DOI: https://doi.org/10.21203/rs.3.rs-438878/v1

License: (9) This work is licensed under a Creative Commons Attribution 4.0 International License. Read Full License

Version of Record: A version of this preprint was published at Climate Dynamics on September 21st, 2021. See the published version at https://doi.org/10.1007/s00382-021-05961-z. 
$9 \quad{ }^{3}$ Bedford Institute of Oceanography, Fisheries and Oceans Canada, Dartmouth, Nova Scotia

10 Canada

11 \#Corresponding author: H.-B. Hu (huhaibo@nju.edu.cn)

\section{Declarations}

\section{$13 \quad$ Funding}

14 This work was supported by the National Key Program for Developing Basic Science (grants 2016 YFA0600303 and 15 2018YFC1505900).

Conflicts of interest/Competing interests

The authors have no conflicts of interest to declare that are relevant to the content of this article.

Writing - original draft: Shunyu Jiang and Haibo $\mathrm{Hu}$

20 Writing - Review and Editing: Haibo Hu and Shunyu Jiang

21 Visualization: Shunyu Jiang 


\section{key points:}

23

24
- Both the Arctic and Antarctic ice covers have trans-equatorial climate effects, which can affect the air temperature in the other hemisphere.

- The interannual variation of Antarctic ice cover even has a greater impact on the surface air temperature over East Asia and North America than the Arctic ice cover.

- The variance of Antarctic ice cover is closer to the atmospheric midlatitude westerly jet, whose interannual changes could cause more generation of significant atmospheric baroclinic waves and trans-equatorial propagation, resulting in the obvious land surface temperature changes over the Asia and North America. 


\section{Abstract}

Ice covers in high latitudes play important role in the global atmospheric circulation and abnormal temperature distribution. The observations have revealed the differences in the interannual variability of the Arctic and Antarctic ice covers, but their respective climate effect is not clear. The Liang-Kleeman information flow method is used to reveal the causal relationships from the sea ices of the Arctic and Antarctic to the global air temperature. The results point out that changes of the Arctic or Antarctic sea ices both have significant impacts on the global air temperature. Especially for the air temperature in East Asia and North America, the interannual variation of the Antarctic sea ice has an even stronger impact than the Arctic ice covers. This causality is further proved by the General Atmospheric Circulation Model (CAM4.0). In the numerical experiments, the ice covers in Arctic and Antarctic are changed individually or simultaneously as the forcing fields, and then the respective climate effects are analyzed. The results show that both the Arctic and Antarctic ice cover variations can change the intensity of atmospheric baroclinic disturbance in mid-high latitudes of individual hemisphere, generating wave energy transmission across the equator in the meridional direction, and eventually causing air temperature anomalies in both hemispheres. Furthermore, the Antarctic ice covers are closer to the mid-high latitude atmospheric jets in the southern hemisphere. Therefore, the changes of Antarctic ice covers lead to a larger atmospheric wave-activity flux response, and quickly spread to the northern hemisphere, causing more significant temperature anomalies over the East Asia and North America.

\section{Key words}

The Liang-Kleeman information flow; trans-equatorial climate effect; atmospheric wave-activity flux; configuration of ice cover and jet stream

\section{Introduction}

As the "cold source" of the entire Earth system, the Antarctic and Arctic regions have significant climate effects and play vital roles in global heat balance (Rosinski et al., 2008). With global warming, the polar region plays a "magnifying glass" to the signal of abnormal climate change and is one of the climate change sensitive areas (Mare, 1997; Zhang, 2005; Wouters et al., 2015). The report of IPCC (The Intergovernmental Panel on Climate Change) pointed out 
that, at the current level of greenhouse gas emissions, the climate in high latitudes will change drastically in the next century, the sea ice will melt, and the temperatures will also continue to warm (Schiavon et al., 2007). The change cycle of Arctic (Antarctic) sea ice has remarkable seasonality, with the maximum (minimum) volume from February to March and the contrary value from August to September (Walsh and Johnson 1979; Cavalieri et al., 1997; Parkinson et al. 1999; Saba et al, 2004). Affected by the global warming, the Arctic has undergone tremendous changes in the past 30 years (Solomon et al., 2007). Since satellite observations SSM / I (the Special Sensor Microwave/Imager)-SSMIS (the Special Sensor Microwave Imager/Sounder) were available in the 1970s, the concentration and coverage of Arctic sea ice have shown a rapid decrease, and the rate has been even faster in recent years (Nghiem et al., 2007). The sea ice in the Arctic Ocean reached its minimum in September 2012, a 31\% decrease from the average of the 1950s and 1970s (Comiso et al., 2008). The melting of Arctic sea ice is closely related to the "Arctic amplification", which is a hot issue in recent years (Overland et al.,1996; Screen and Simmonds, 2010). In recent decades, the temperature in the Arctic has increased twice as large as the global average rate, and this phenomenon is called the "Arctic amplification" (James and Ian, 2010; Kim et al.,2016). A large number of simulation studies have pointed out that under a representative global warming scenario, the temperature increase will be amplified in the polar regions, and the rainfall increase will reduce the salinity of the upper Arctic ocean (Manabe and Stouffer, 1994; Rind et al., 1995; Wu and Smith, 2016). The Arctic amplification has also caused more frequent blocking patterns and extreme weather (Elizabeth, 2013). In addition, ice cover in Antarctic has also changed significantly. Compared with Arctic sea ice, Antarctic sea ice has more movement freedom and has an important impact on atmospheric stability and precipitation in Antarctica (King, 1997). Due to the thick snow and ice deposits on the Antarctic ice cap, the volume of snow and ice in the southern hemisphere is about 8.8 times than that of the northern hemisphere (Cavalieri et al., 1997, 1999, 2003). Unlike the rapid decrease in Arctic sea ice, the Antarctic sea ice has been growing slowly and lasting longer (Stammerjohn et al., 2012). The sea basin of the Arctic sea ice shrinks rapidly, while the Antarctic sea ice shows regional changes. Cavalieri et al. (2003) used several sea ice observations of satellite from 1972 to 2002 to analyze the changes in the sea ice extent of Antarctica. The study found that the sea ice area of Antarctica showed a decreasing trend from 1973 to 1977 , but there was an increasing trend from 1977 to 2002. Further studies showed that 
the sea ice in the Ross Sea, Weddell Sea, and the eastern coast of the Antarctic continent has increased year by year, while the sea ice in the Bellinghausen Sea and Amundsen Sea has decreased (Cavalieri and Parkinson, 2008; Comiso and Nishio, 2008; Fan et al., 2014).

Compared with the research on long-term trend changes accompanying global warming, the significant interannual changes of sea ice had attracted more attention, both in the local region and hemisphere (Parkinson and Cavalieri, 1989; Lindsay and Zhang, 2004; Screen et al., 2011). In 2007, the Arctic sea ice reached a new record low, and the extent of sea ice in the autumn of that year was reduced by 23\% (Stroeve et al.,2008). This record was refreshed in September 2012, which was 12\% lower than the lowest value in 2007 (Zhang et al., 2013). During the 2016/2017 icing period, the Arctic had 15 days of sea ice reduction, which was the most since 1979 (Hegyi and Taylor, 2018). In February, the sea of Okhotsk experienced the largest interannual variability, while in July, the interannual variability in the Hudson Bay and northern Barents Sea was particularly large (Claire and Parkinson, 1991). The Antarctic sea ice cover has a very significant annual change, and its smallest range is only $1 / 10$ to $1 / 20$ of the largest range, and different years show very different or even opposite trends (Cavalieri et al.,2003). Between 1973 and 1977, Antarctic sea ice decreased dramatically, with an average annual decrease of about $2 \times 10^{6} \mathrm{~km}^{2}$, but from 1977 to 2002 , the distribution range of sea ice gradually increased at a rate of $(0.10 \pm 0.05) \times 10^{6} \mathrm{~km}^{2} / 10 \mathrm{a}$ (Zwally et al.,2002). The interannual variability of sea ice in the Arctic and Antarctica is complicated, and the interannual variability of ice cover in the Arctic and Antarctic regions is not synchronized. For example, the annual averages of the ocean ice surface area of the two polar regions are very similar over the period 1979-2012, but in fact the temporary evolution in sea ice in the two hemispheres are opposite (Pérez and González, 2014). Furthermore, the interannual variabilities of ice covers in the Arctic and the Antarctic are significantly different (Gloersen and Campbell, 1991; Gloersen et al., 1992; Stammerjohn et al., 2012). However, the mechanism and climate effects of the ice covers in polar regions are currently unclear.

The couple relationship between ice covers and the local atmosphere in polars has been concerned widely. For example, Francis and Hunter (2006) found that the location of the Arctic sea ice edge in summer has a strong correlation with the long-wave energy emitted by the atmosphere. And the greenhouse effect caused by downward long-wave radiation is amplified in 
the process of polar warming, which caused significant changes of the Arctic sea ice in summer from 1979 to 2004. In addition, temperature anomalies, local wind field anomalies (Comiso et al., 2008), atmospheric circulation, polar cloud cover (Palm et al., 2010), and sea surface temperatures (Kay et al., 2009 Alekseev et al., 2017) will have an impact on the thickness, coverage and intensity of the Arctic sea ice. Simmonds and Jacka (1995) discovered that the sea ice along the Antarctic continent, the Southwest Indian Ocean, the South Pacific, and the western Ross Sea interact with Southern Oscillation (SO). In addition, the Antarctic sea ice changes will also be affected by multiple factors such as temperature, carbon dioxide concentration, El Niño, and solar radiation (Gloersen, 1995; Yuan and Martinson, 2001; De Magalhães et al., 2012). In addition, the interannual changes of ice cover in the polar regions have been proved to change the energy balance of the ocean surface, local air temperature and atmospheric circulation (White and Peterson, 1996; Allison, 2000; Francis and Vavrus, 2012; Liu et al., 2013; Gao et al., 2015; Cheung et al., 2018). The reduction of Arctic ice cover makes the lower troposphere warmer and unstable, the cloud cover increases and the polar thickness gradient weakens, which weakens the polar jet (Francis et al., 2009). Researches (Liu et al., 2001; Nakamura et al., 2015; Caian et al., 2017) pointed out the influences of Arctic sea ice on the phase and intensity of the North Atlantic Oscillation (NAO) and Arctic Oscillation (AO). The negative phase of NAO caused by the changes in sea ice in recent years has led to the cold winter in Europe (Cattiaux et al., 2010). In summer, the change of sea ice causes a positive phase of AO, which makes cold air shrink to the polar regions, and the temperature in most parts of the northern hemisphere is warmer (Jiang et al., 2019). At the same time, the transport of polar cold air to mid-latitudes and marine cold air outbursts (MCAOs) will change affect the climate of Eurasian continents at mid-high latitudes (Liu et al., 2006; Kolstad et al., 2008). The ice cover in the Arctic will affect the local and northern hemisphere temperature by changing the NAO and $\mathrm{AO}$, and the interannual variation of the ice cover in the Antarctic also has an impact on the climate in the southern hemisphere. Changes in the Antarctic sea ice will cause anomalies in regional atmospheric circulation, which will then propagate through wave trains or disperse energy to affect the weather and climate systems at the mid and low latitude areas in the southern hemisphere (Horel and Wallace, 1981; Gloersen et al., 1992; Watkins and Simmonds, 1998; Liu et al., 2004). It can be seen that the sea ice of the North and South Poles has been considered to be the main forcing factor of long-term 
climate change or abnormal temperature events on interannual time scales in their respective hemispheres.

In addition to the influences of ice covers in polars on the climate in each hemisphere, the sea ice was proved to have a trans-equator climate effect on the other hemisphere, which might affect the occurrence of local extreme climate events. Rogers et al. (1979) found that sea ice affects planetary waves in the upper and middle troposphere, and pointed out that the location of large-scale sea ice anomalies is consistent with the interannual variation of large-scale planetary wave changes in the upper and middle troposphere. When Liu and Fedorov (2019) used climate models to study the impact of Arctic sea ice reduction, they found that the climate effect would change over time. During the initial period of Arctic sea ice reduction, the northern hemisphere became warmer and the southern hemisphere became colder, the tropical convergence zone moved northward, and the Antarctic sea ice expanded, but the opposite was true when the time scale became longer. The actual observation results also confirmed this. The satellite, groundbased, and reanalysis data over the past 40 years (1980-2019) show that since the end of the 1970s, with the rapid decrease of Arctic sea ice, the temperature in the Southern Hemisphere has decreased regionally, but after 2016, the situation was reversed, and the Antarctic sea ice began to decrease sharply (Mokhov and Parfenova, 2021). Antarctic sea ice was found to have a good connection with the atmospheric circulation in the northern hemisphere (Kwok and Comiso, 2002; Martinson and Douglas, 2003). Furthermore, researches pointed out the abnormal transequatorial cold airflow in the South Indian Ocean and Australia in different years of Antarctic ice coverage (Christopher et al., 1996; Xue et al., 2003). Jie et al (Jie et al., 2009) pointed out that the Antarctic Oscillation (AAO) anomaly could trigger Pacific/North American teleconnection patterns (PNA) like quasi-stationary Rossby waves by affecting the tropical zonal wind.

Therefore, the Antarctic sea ice anomaly had a good correlation with the East Asian monsoon and rainfall (Yang, 1992; Qin et al., 2014). Regarding the steady Rossby wave propagation across the equator, Li et al. (2019) determined the obstacle area and corresponding waveguide as each window area in the northern hemisphere winter and summer tropospheric high-level wave propagation across the equator. These waveguides may be the main channels for energy exchange between the two hemispheres. The eastern Pacific Ocean is the window area that exists in both winter and summer, and the Rossby waves can cross the equator through this window area. However, there remains several questions have not been well solved. Previous studies have 
emphasized that changes in sea ice can lead to significant climate effects, but there are significant differences in the interannual changes in ice cover between the Arctic and the Arctic in actual observations. How do the different interannual changes of the Arctic and Arctic ice cover affect the temperature? In the earth system, sea ice interacts with the atmosphere and ocean. How to extract the forcing signal of sea ice on air temperature in the complex earth coupling system? The Rossby wave and cold air activity across the equator are thought to be the possible causes of the forcing of the polar sea ice on the other hemisphere, but can the Arctic and Antarctic ice cover drive the same intensity of trans-equal forcing? What are the specific impacts on the temperature distribution in the two hemispheres? In particular, what is the difference in the process and mechanism of the Rossby wave triggered by changes in the ice cover at the two poles?

Based on the above question, this paper will use Liang-Kleeman information flow (Liang 2014,2015) method and model simulations to discuss. A more specific introduction about the Liang-Kleeman information flow method will be explained in detail in the section of data and method, which is used to give the causal relationship from the Arctic and Antarctic sea ice to the air temperature change, and then the Community Atmosphere Model version4.0 (CAM4.0) is used to discuss the influence mechanisms of Arctic and Antarctic ice cover on climate. The following are the section arrangements of this paper: Section 2 describes the data and method, including the calculation of the Liang-Kleeman information flow, T-N Wave-activity flux, Eady growth rate and introduction of the CAM4.0; Section 3 analyzes the influence of interannual variation of ice covers in two polars on temperature in observation and simulation; Section 4 analyzes the mechanism of trans-equatorial climate effect of interannual variation of ice covers on the other hemisphere; Section 5 summarizes and discusses.

\section{Data and method}

\subsection{Data}

The sea ice data used in this paper are the OISST (Optimum Interpolation Sea Surface Temperature) monthly data of NOAA (National Oceanic and Atmospheric Administration) (https://www.esrl.noaa.gov/psd/data/gridded/data.noaa.oisst.v2.html). The horizontal resolution 
212 is $1^{\circ *} 1^{\circ}$, from January 1982 to December 2017. The temperature data is monthly surface

213 temperature from NCEP (National Centers for Environmental Prediction)/NCAR (National

214 Center for Atmospheric Research) reanalysis data, and the horizontal resolution is $2.5^{\circ} * 2.5^{\circ}$,

215 from January 1948 to December 2017

216 (https://www.esrl.noaa.gov/psd/data/gridded/data.ncep.reanalysis.surface.html).

2.2 Method

\subsubsection{Liang-Kleeman information flow and time series causal analysis}

Analyzing the causal relationship between events is an important topic in many disciplines, and it is the direct purpose of many scientific researches. In meteorology, most methods use time lag correlation analysis to infer the causality between series. However, correlation analysis does not distinguish the directionality, and for a periodic process, we cannot judge whether a phase difference is time lag or time advance. For example, in a fluctuation period of $\mathrm{T}$, the lag $\mathrm{t}$ is the same as the lead T-t. The sequence constructed by Liang (2014) is an example, which proves that the cause and effect given by the lead-lag correlation is completely opposite to the actual situation. Liang proposed the theory of information flow, and analyzed the causal relationship between events through the method of Liang-Kleeman information flow (Liang 2014,2015). This method has been widely used since it was proposed (Stips et al. 2016; Liang 2018; Jiang et al. 2019). The causality of a given two time series can be judged by the Liang-Kleeman information flow theory. The information flow has always been considered as an appropriate measure of causality, as the exchange of information between two events, not only indicates the quantity, but also the direction of the causality (Liang, 2014). Liang $(2014,2015,2016)$ proved that if the development of $X_{1}$ is independent of $X_{2}$, then the information flow from $X_{2}$ to $X_{1}$ is 0 . For linear systems, given two time series of $X_{1}$ and $X_{2}$, Liang proves that the maximum likelihood estimator (mle) of information flowing from $X_{2}$ to $X_{1}$ per unit time is

$$
\widehat{T}_{2 \rightarrow 1}=\frac{C_{11} C_{12} C_{2, d 1}-C_{12}^{2} C_{1, d 1}}{C_{11}^{2} C_{22}-C_{11} C_{12}^{2}}
$$

Where $C_{i j}$ is the sample covariance between $X_{i}$ and $X_{j}, C_{i j}:=\overline{\left(X_{l}-\bar{X}_{l}\right)\left(X_{J}-\bar{X}_{J}\right)}$

$\mathrm{C}_{i, d j}$ is the sample covariance between $X_{i}$ and a series derived from $X_{j}$ using the Euler forward differencing scheme, $\dot{X}_{j, n}=\frac{X_{j, n+k}-X_{j, n}}{k \Delta t}, \Delta \mathrm{t}$ is the time step and $\mathrm{k} \geq 1$ (integer). If $T_{2 \rightarrow 1}=$ 
$0, X_{2}$ does not cause $X_{1}$; if it is not equal to zero, it is causal (statistical significance test must be performed). The calculation program of this information flow can be downloaded through http://www.ncoads.cn/article/show/63.aspx. This method has been widely recognized and applied. Jiang et al. (2019) used the Liang-Kleeman information flow and CAM4.0 to analyze the climate effect of multi-source forcing.

\subsubsection{T-N Wave-activity flux}

The TN wave-activity flux is a three-dimensional wave-activity flux derived by Takaya and Nakamura $(1997,2001)$ based on the Plumb wave flux, making it more suitable for complex background airflow, such as the background circulation in the middle and high latitude. The background field takes the average monthly climate field for many years, which can better describe the energy dispersion characteristics of the stationary Rossby wave and the propagation anomaly of the Rossby wave. The three-dimensional expression of the $\mathrm{T}-\mathrm{N}$ wave-activity flux is as follows:

$$
\mathrm{W}=\frac{p \cos \varphi}{2|\boldsymbol{U}|} \cdot\left(\begin{array}{c}
\frac{U}{a^{2} \cos ^{2} \varphi}\left[\left(\frac{\partial \psi^{\prime}}{\partial \lambda}\right)^{2}-\psi^{\prime} \frac{\partial^{2} \psi^{\prime}}{\partial \lambda^{2}}\right]+\frac{V}{a^{2} \cos \varphi}\left[\frac{\partial \psi^{\prime}}{\partial \lambda} \frac{\partial \psi^{\prime}}{\partial \varphi}-\psi^{\prime} \frac{\partial^{2} \psi^{\prime}}{\partial \lambda \partial \varphi}\right] \\
\frac{U}{a^{2} \cos \varphi}\left[\frac{\partial \psi^{\prime}}{\partial \lambda} \frac{\partial \psi^{\prime}}{\partial \varphi}-\psi^{\prime} \frac{\partial^{2} \psi^{\prime}}{\partial \lambda \partial \varphi}\right]+\frac{V}{a^{2}}\left[\left(\frac{\partial \psi^{\prime}}{\partial \varphi}\right)^{2}-\psi^{\prime} \frac{\partial^{2} \psi^{\prime}}{\partial \varphi^{2}}\right] \\
\frac{f_{0}^{2}}{N^{2}}\left\{\frac{U}{\operatorname{acos} \varphi}\left[\frac{\partial \psi^{\prime}}{\partial \lambda} \frac{\partial \psi^{\prime}}{\partial z}-\psi^{\prime} \frac{\partial^{2} \psi^{\prime}}{\partial \lambda \partial z}\right]+\frac{V}{a}\left[\frac{\partial \psi^{\prime}}{\partial \varphi} \frac{\partial \psi^{\prime}}{\partial z}-\psi^{\prime} \frac{\partial^{2} \psi^{\prime}}{\partial \varphi \partial z}\right]\right\}
\end{array}\right)
$$

Where the superscript " ' " is zonal deviation, $\varphi 、 \lambda 、 \Phi 、 f=2 \Omega \sin \varphi$ 、 a $\Omega$ are latitude,

256 longitude, potential, Coriolis parameter, earth radius and earth rotation rate, $\psi^{\prime}=\frac{\Phi^{\prime}}{f}$ is the 257 perturbation of the quasi-ground transfer function relative to the climate field, and the basic flow 258 field $\mathrm{U}=(\mathrm{U}, \mathrm{V})$ represents the climate field. It is widely used to analyze the propagation of Rossby waves in atmospheric dynamics (Nakamura et al. 2010).

In the classical theory of atmospheric stability, the baroclinicity of the atmosphere is defined by the horizontal temperature gradient, the Coriolis force on the vertical shear and 
vertical stability of the horizontal velocity. In the original situation, the growth rate of baroclinic pressure, which characterizes the instability of atmospheric baroclinic pressure, is defined as

$$
\sigma_{B I}=0.31 \frac{|f|}{N} \frac{\partial U}{\partial z}
$$

When Hoskins and Valdes (1990) researched the storm track in the northern hemisphere, simplified it to:

$$
\sigma_{\mathrm{BI}}=0.31 \frac{\mathrm{g}}{\theta \mathrm{N}}\left|\frac{\partial \theta}{\partial \mathrm{y}}\right|
$$

In which, $\mathrm{f}=2 \Omega \sin \varphi$ is the Coriolis parameter, $\mathrm{U}$ is the zonal wind, $\theta$ is the potential

temperature, $\alpha=\frac{\mathrm{T}}{\theta \mathrm{T}_{\mathrm{p}=1000}}, \mathrm{~N}^{2}=-\mathrm{g} \alpha \frac{\partial \theta}{\partial \mathrm{p}} \cdot \mathrm{N}^{2}$ is the Brunt-Vaisala frequency of atmosphere, also called buoyancy frequency, which indicates the frequency at which the gas block oscillates when it is vertically disturbed. $\mathrm{N}^{2}$ can be used to measure stability. In recent years, this simplified version has been widely used (Chen et al., 2020). This paper uses (3) to calculate the eady growth rate, represented the baroclinicity of the atmosphere.

\subsubsection{Model introduction}

In addition to statistical analysis of observational data, model simulations can provide a more detailed description of the physical processes in climate change. CAM4.0 (Community Atmosphere Model version4.0) is a global atmospheric circulation model developed by NCAR (National Center for Atmospheric Research) (Neale 2010; Gent 2011). Existing research results show that CAM4.0 has good simulation capabilities for global atmospheric circulation and climate change, and has also been widely used (Neale et al. 2013; Chen et al. 2016; Niranjan Kumar et al. 2016). CAM4.0 also includes the land surface model (CLM4.0), which provides the land surface conditions and lower boundary conditions such as energy, momentum, and water vapor exchange between land and air (Oleson, 2010). Three power cores are optional: the Euler spectrum core, the finite volume core and the half Lagrangian core. The Euler spectrum is be used in this paper, and the horizontal resolution of the model used is T85 (128*256, about 1.5 degrees). In the vertical direction, the coordinates used from bottom to top are the $\sigma$ coordinates, the $\sigma-p$ transition coordinates, and the pure p coordinate, covering 26 layers. The deep convection process is used a parametric scheme developed by Zhang and McFarlane (1995) and 
corrected by Richter and Rasch (2008). Compared with CAM3.0, CAM4.0 has significantly improved on deep convection scheme, Arctic cloud simulation, radiated interface and computational scalability. What's more, its default power core has been changed from the original spectral core to a finite volume core, and improves simulation capabilities for ENSO (Neale et al, 2008).

\section{The influence of interannual variation of polar ice cover on temperature}

\subsection{Liang-Kleeman information flow and observation results}
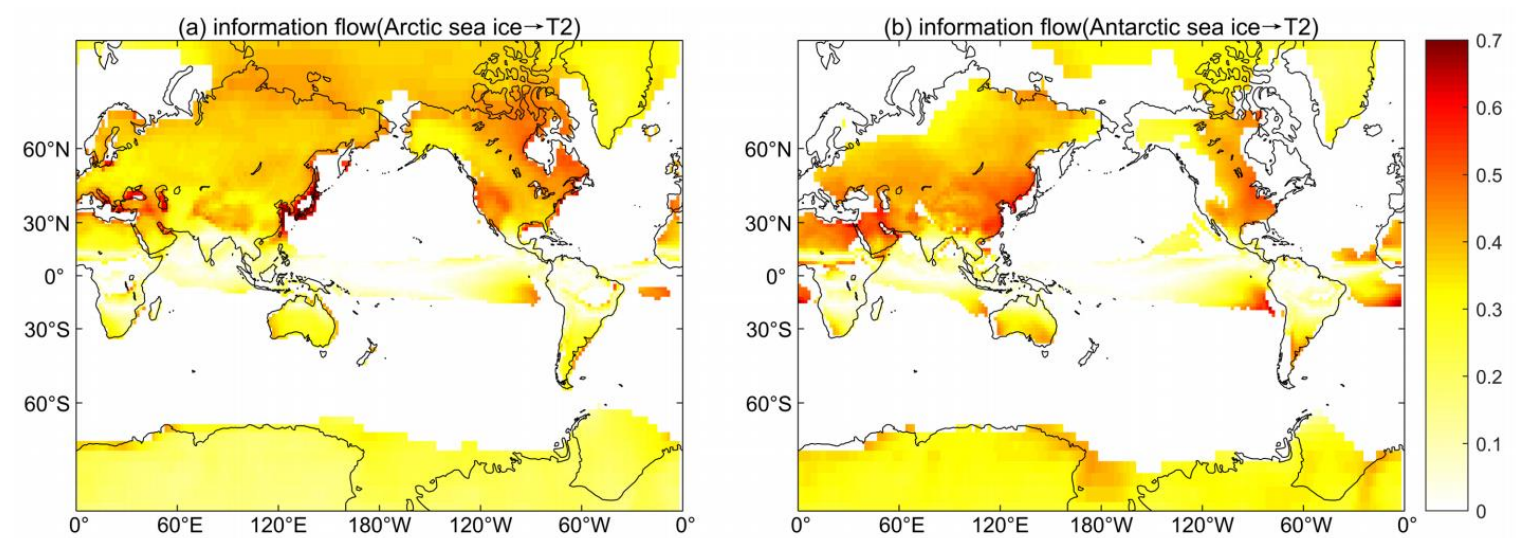

Fig. 1. Spatial distribution of information flow from (a) Arctic sea ice (b) Antarctic sea ice to the $2 \mathrm{~m}$ temperature (filling; unit: nats/month). All shading areas exceed 95\% significance level.

In order to discuss the influence of sea ice in the Arctic and Arctic on the temperature in different regions, we calculated the spatial distribution of the information flow from sea ice to temperature by the Liang-Kleeman information flow method. Fig. 1 showed that there are obvious causal relationships from the Arctic and Antarctic sea ice to the temperature, the temperature change is closely related to the sea ice anomaly. Changes in Antarctic and Arctic sea ice have an impact on the temperature in the other hemisphere. Temperature changes in Asia and North America are also closely related to Antarctic sea ice, and the response to Antarctic sea ice in East Asia is even more pronounced than that of Arctic sea ice. Whether Antarctic sea ice has a greater impact on the above areas is also analyzed from observations. 


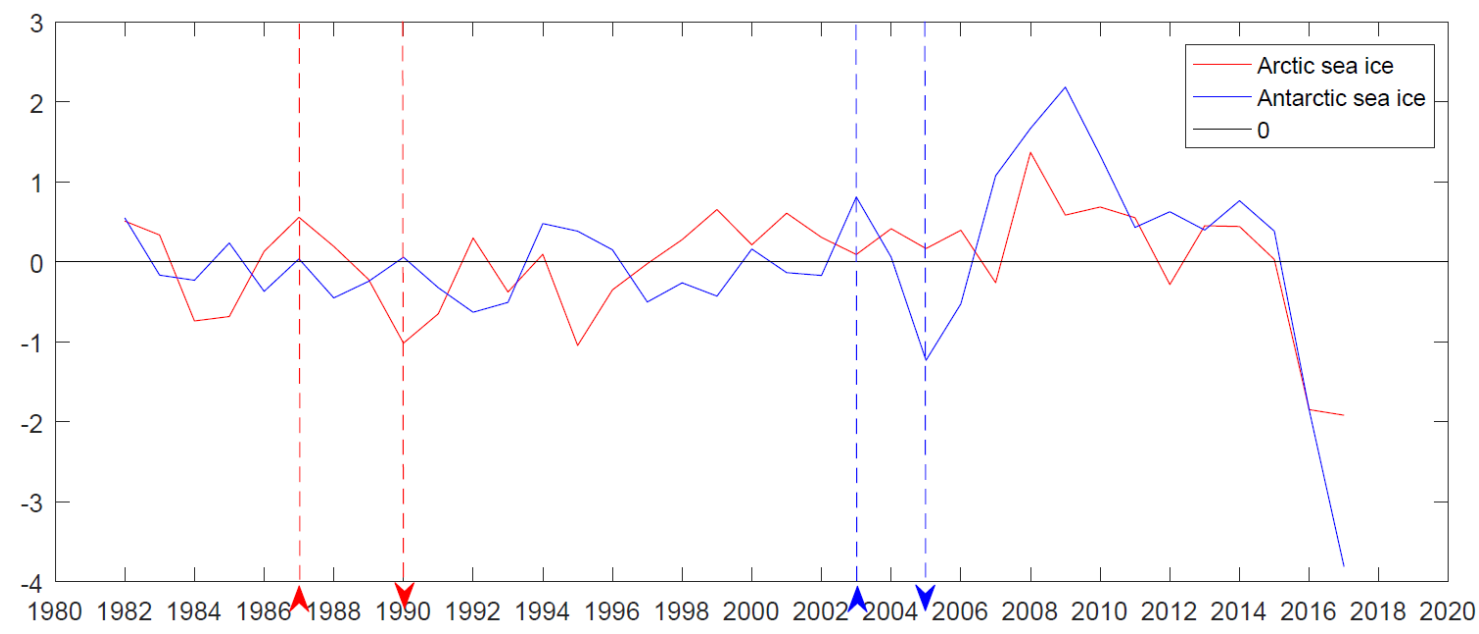

313 Fig. 2. Line chart of changes in Arctic and Antarctic sea ice relative to the average (the index has 314 been standardized and detrended; red line: Antarctic sea ice; blue line: Arctic sea ice; unit:

315 fraction; the red up/down arrow: Arctic sea ice increases/decreases abnormally; the blue up/down 316 arrow: Antarctic sea ice increases/decreases abnormally)

From 1982 to 2017, the year 1987 and 1990 are selected as the Arctic sea ice anomaly year, 319 in which the Arctic sea ice changes significantly and the Antarctic sea ice is almost unchanged.

320 Similarly, the year 2003 and 2005 are selected as the Antarctic sea ice anomaly year (Fig. 2). We 321 analyze the temperature changes in these years to discuss the climate response of sea ice 322 reduction. Fig. 3 shows the spatial distribution of the difference in temperature between the year 323 of anomalous decrease and anomalous increase in sea ice. 

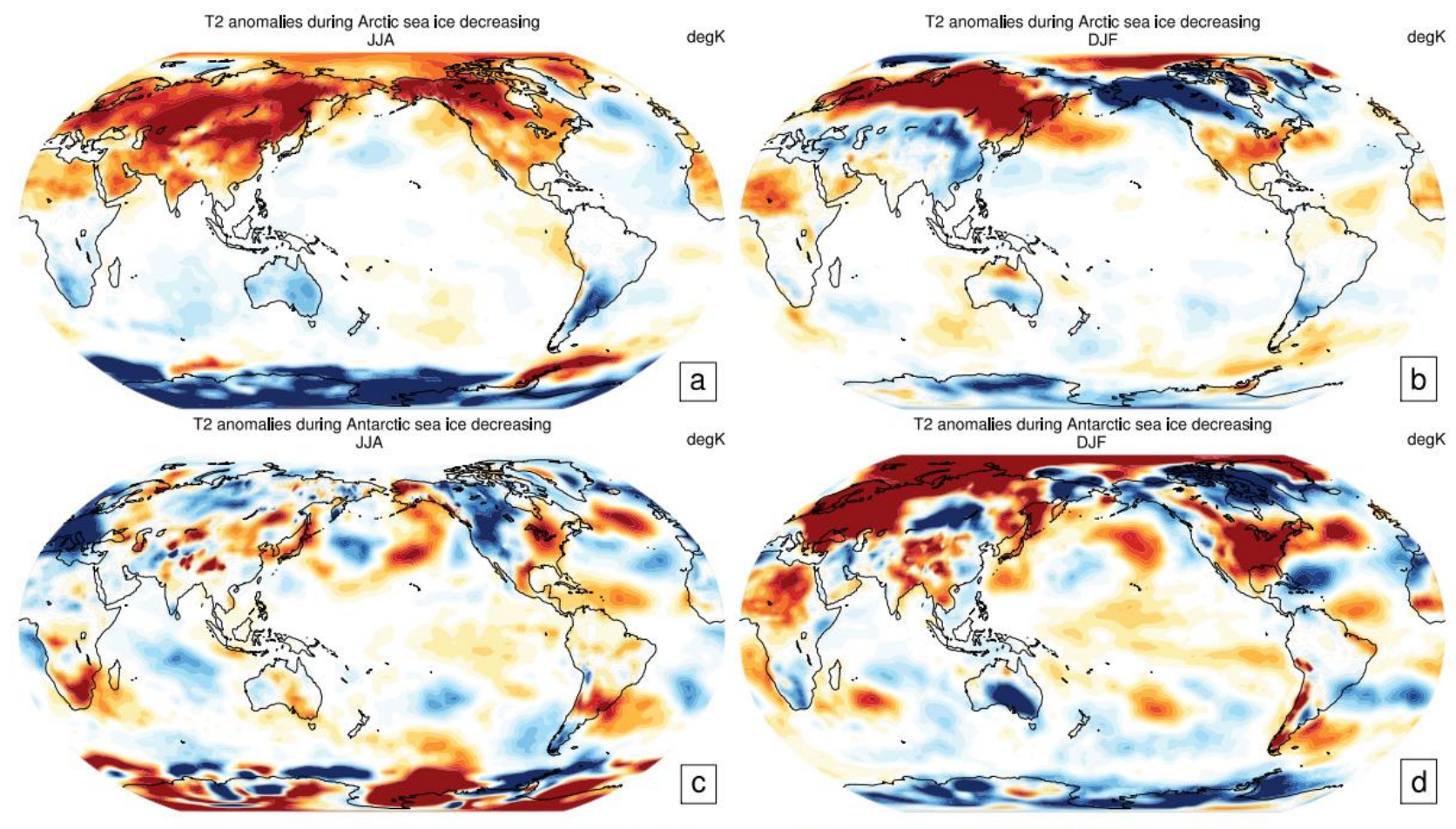

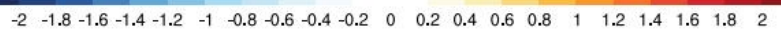

Fig. 3. Spatial distributions of temperature changes different between the decrease anomalous years and the increase anomaly years of sea ice. T2 anomalies during Arctic sea ice decreasing in (a) summer average (b) winter average; T2 anomalies during Antarctic sea ice decreasing in (c) summer average (d) winter average (filling; unit: K).

In different seasons (summer and winter) of the anomaly years of sea ice, the temperature changes have obviously different spatial distributions (Fig. 3). Considering that sea ice has a tendency to decrease, we do not discuss temperature changes in the polar regions, but mainly discuss the temperature changes in Eurasia and North America. When the Arctic sea ice decreases abnormally, the temperature of Eurasian increases significantly in summer, but in winter it heats up in the north and cools down in the south. For North America, it's warm up in summer, but in winter the north (Canada) cools, while the south (USA) warms. In addition, the temperature in the southern hemisphere is also affected, and there are cooling trends in Oceania and southern South America. When the Antarctic sea ice decreases abnormally, there is no doubt that it will bring about a significant temperature change in the southern hemisphere, and it will 
340 also affect the temperature of the northern hemisphere. In the year of Antarctic sea ice abnormal 341 decrease, the most regions of East Asia have a clear warming trend, but the north regions have a cooling trend, which is consistent in summer and winter. Regardless of summer or winter, North America shows a trend of decreasing temperature in the north and increasing temperature in the south. Through the actual observation, the Arctic and Arctic sea ice have obvious transequatorial climate effects, and the effects of the two are quite different in some areas. Therefore, it is meaningful to discuss the climate effects of ice cover in the Arctic and Arctic regions separately by using the CAM4.0 model.

\subsection{Temperature changes in the simulation}

The experiments using the CAM4.0 are designed to study the climate response of Arctic and Antarctic ice cover. Therefore, we set up a control experiment and several contrast experiments by changing the forcing field, and Table 1 shows the specific experiment settings. The time scale of the observation data used in this article is 70 years from 1948 to 2017. The difference between the next 35 years (1948-1982) and the previous 35 years (1983-2017) represents the actual observational changes when analyzing. Therefore, we use the situation in 2000 (the middle year of 1983-2017) as the forcing field for the control experiment, and the situation in 1965 (the middle year of 1948-1982) as the forcing field for the contrast experiments.

Table 1. Experiment design

\begin{tabular}{|c|c|}
\hline Experiment & Description of the forcing fields \\
\hline CTRL & $\begin{array}{l}\text { All forcings }\left(\mathrm{CO}_{2} \text {, land cover, ice cover, } \mathrm{SST}\right) \text { are fixed to the year } \\
2000\end{array}$ \\
\hline SIC & $\begin{array}{l}\text { Same as CTRL but the ice cover (both the Arctic and Antarctic) is } \\
\text { fixed to the year } 1965\end{array}$ \\
\hline NSIC & $\begin{array}{l}\text { Same as CTRL except the Arctic ice cover is fixed to the year } \\
1965\end{array}$ \\
\hline SSIC & $\begin{array}{l}\text { Same as CTRL except the Antarctic ice cover is fixed to the year } \\
1965\end{array}$ \\
\hline
\end{tabular}




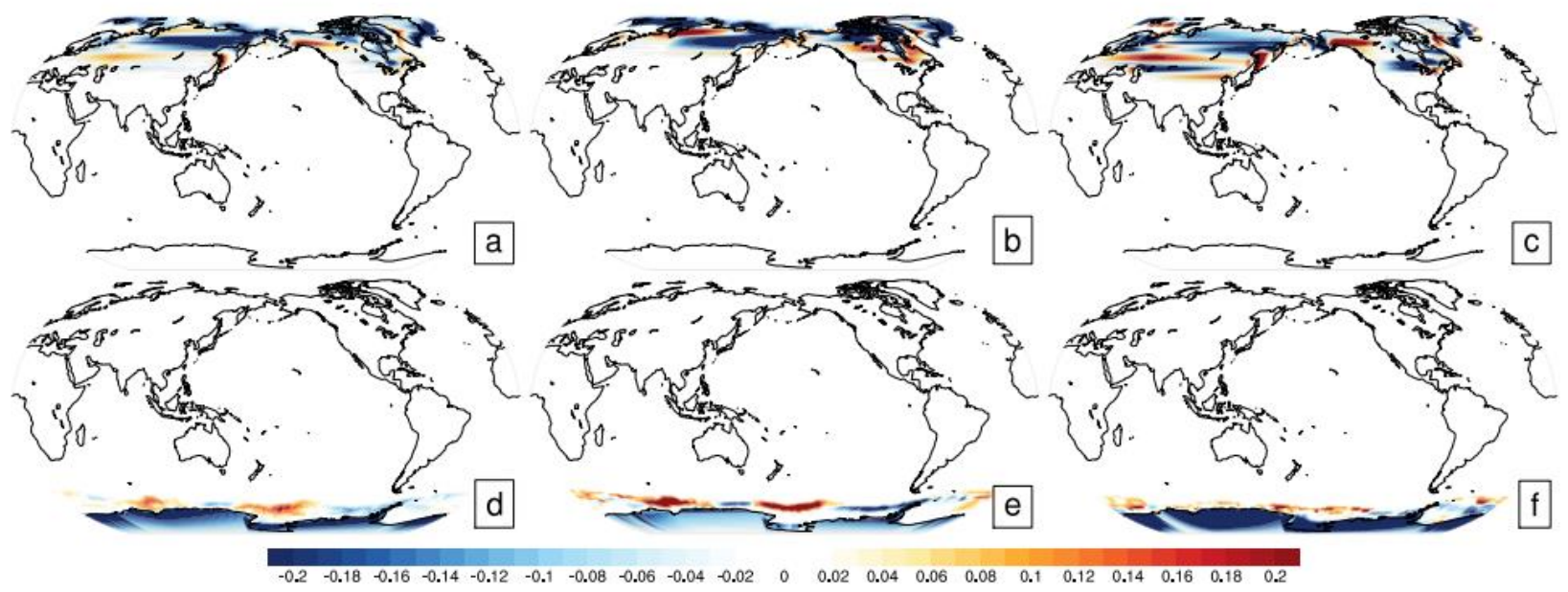

Fig. 4. Changes of ice cover forced field between control (year 2000) and contrast experiments (year 1965). Spatial distribution of Arctic ice cover change: (a) annual average (b) summer average (c) winter average; Spatial distribution of Antarctic ice cover change: (d) annual average (e) summer average (f) winter average (filling, unit: fraction). reduced (Fig. 4). We change the ice cover of the forcing field at the Arctic and Antarctic separately to distinguish the climate effects they bring. In addition, the experiments of changing the ice cover of the Arctic and Antarctic separately is compared with that of changing the ice cover of the two poles at the same time to judge whose influence is more important. 


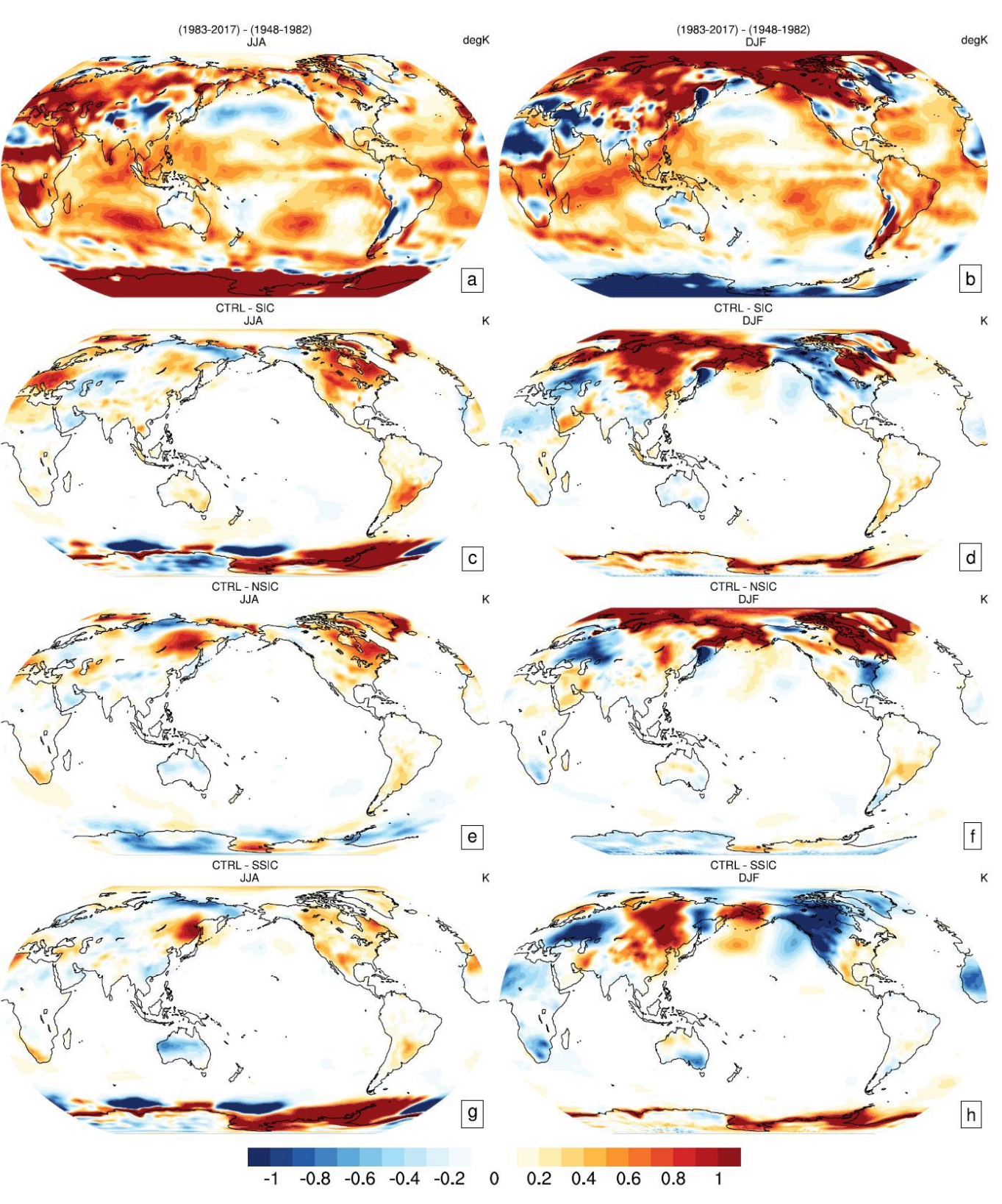

373

Fig. 5. 2m temperature. Difference between (a-b) 1983-2017 and 1948-1982. Difference between control and contrast experiments. (c-d) SIC, (e-f) NSIC, (g-h) SSIC (filling, unit: K; left column: annual average, right column: winter average). All shading areas exceed 95\% significance level.

In observations, the $2 \mathrm{~m}$ temperature generally shows an increasing trend, and some regions in Europe, Asia and North America have cooled (Fig. 5a, Fig. 5b). It can be seen from the simulation results that when the Arctic ice cover and Antarctic ice cover are changed at the same time (the experiment SIC), the temperature in winter changes drastically, and the temperature in Asia obviously increases, while the temperature in North America and Europe decreases (Fig. 5c, 
Fig. 5d). After changing the Antarctic ice cover and Arctic ice cover, it can be seen that compared to NSIC(Fig. 5e, Fig. 5f ), the simulation results of SSIC (Fig. 5g, Fig. 5h) is closer to the simulation results of SIC(Fig. 5c, Fig. 5d), including the warming in East Asia and the cold winter in North America. Changes in Arctic ice cover have caused more pronounced cooling in winter in Europe, and also brought winter warming in parts of South America (the warming is even wider than the temperature increase caused by changes in Antarctic ice cover) (Fig. 5e, Fig. 5f). It can be seen that whether changes in Arctic ice cover or Antarctic ice cover will affect the other hemisphere across the equator. Antarctic ice cover has a greater impact on East Asia and North America than Arctic ice cover. Why does the Arctic/Antarctic ice cover change have a huge impact on the temperature in the Southern/Northern Hemisphere, bringing about a transequator climate effect? Why the trans-equatorial climate effect of Antarctic ice cover is stronger than that of Arctic ice cover? We will analyze the mechanism of this trans-equator climate response below.

\section{Mechanism of Trans-Equatorial Climate Effect of Interannual Variation of Ice Cover}

The previous section analyzed the temperature changes caused by the ice cover in the Arctic and Antarctic, and what is the mechanism of this trans-equatorial climate effect? The existence of the window area allows the Rossby wave to propagate across the equator, and these waveguides may be the main channels for energy exchange between the two hemispheres (Li et al, 2019).When the Arctic ice cover decreases, the temperature in the polar regions increases, the zonal temperature gradient decreases, and the baroclinity of the atmosphere weakens, resulting in a reduction in wave-activity flux (Fig. 6). Therefore, an obvious wave-activity flux reduction area appeared in the North Pole in first month, and the place where the wave-activity flux changed most drastically corresponds to the place where the ice cover changed drastically. At this time, because the Antarctic ice cover has not changed, it can be seen that there is almost no change in wave-activity flux in the southern hemisphere, and the wave-activity flux will gradually pass to the south over time. As can be seen from the spatial distribution of the 300hpa height anomaly field (Fig. 7), when the ice cover in the Arctic changes, the height field anomaly (time 0) first appears in Eurasia, causing baroclinic fluctuations. The wave gradually passed southward and spread across the equator to the southern hemisphere, while separating another 
411 wave, the branch gradually passed eastward to the Americas and continued to pass southward.

412 The change of ice cover first causes the change of the temperature gradient of the lower layer,

413 causing the abnormal atmospheric baroclinic instability, resulting in the generation and

414 propagation of atmospheric baroclinic fluctuation anomalies. This anomalous signal of ice

415 coverage interacts with the wave current of high-altitude atmospheric jets through the baroclinic

416 wave flux and further amplifies, generating meridional waves and even transmitting Rossby

417 waves across the equator.

\section{Baroclinic eddy growth rate}
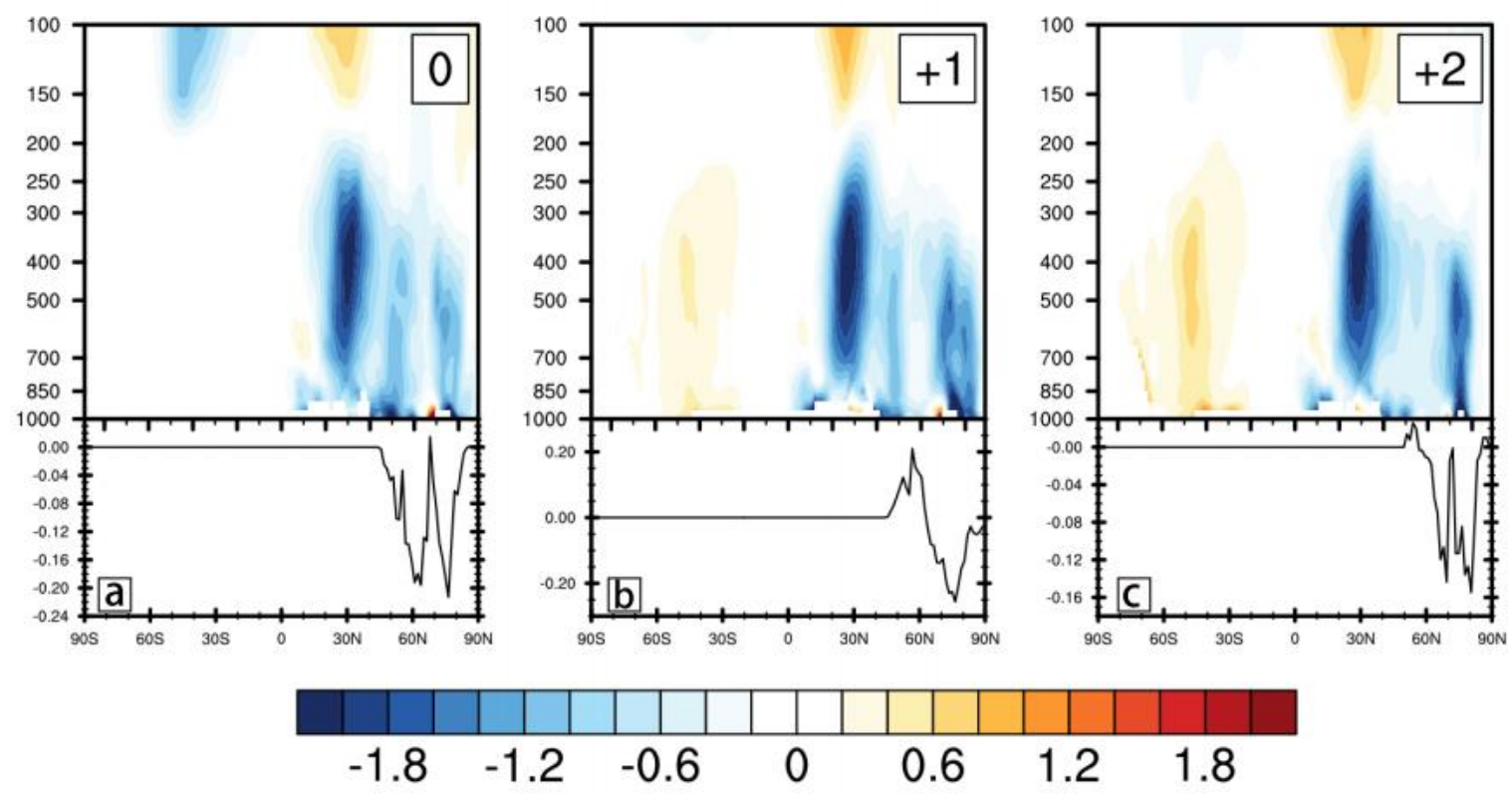

Wave-activity flux
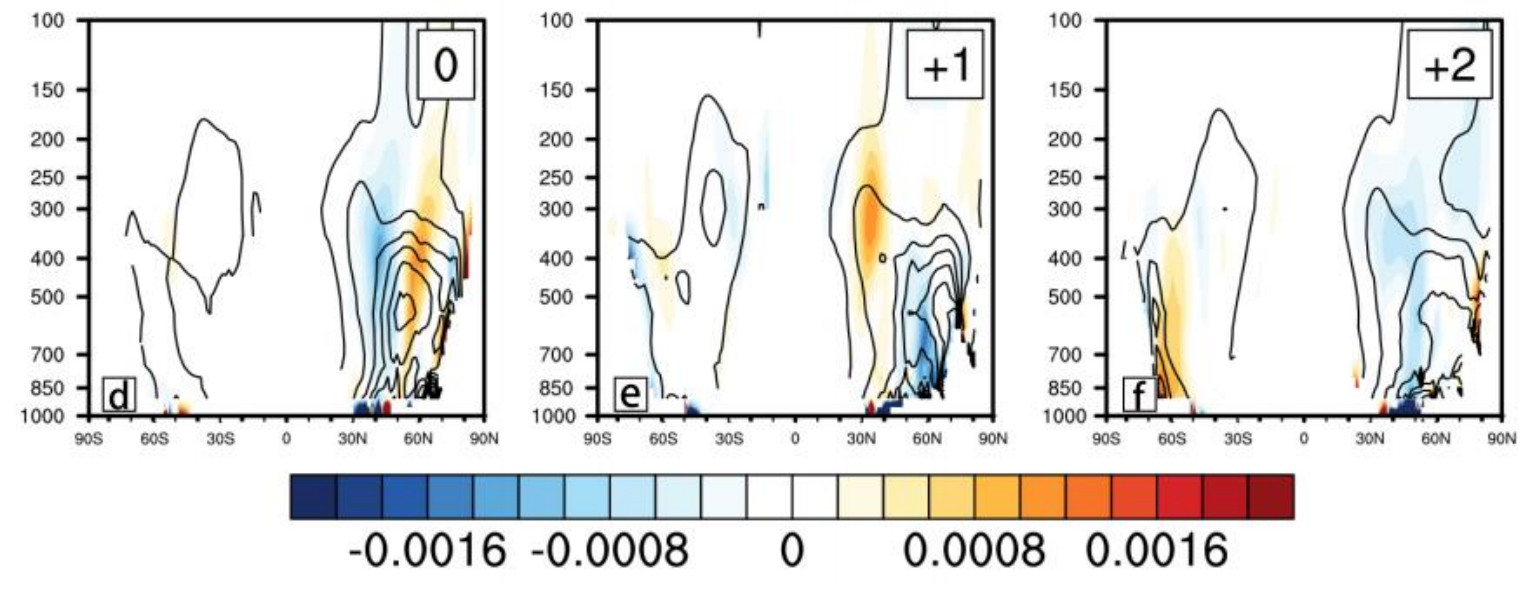
Fig. 6. Vertical section of the difference in meridional mean (a-c) baroclinic growth rate and changes in Arctic ice cover (d-f) wave-activity flux between CTRL and NSIC, changes in Arctic ice cover in the forced field by month (filling, contour line: wave-activity flux distribution in CTRL, polyline: ice cover change with latitude, superscript: month). All shading areas exceed $95 \%$ significance level.
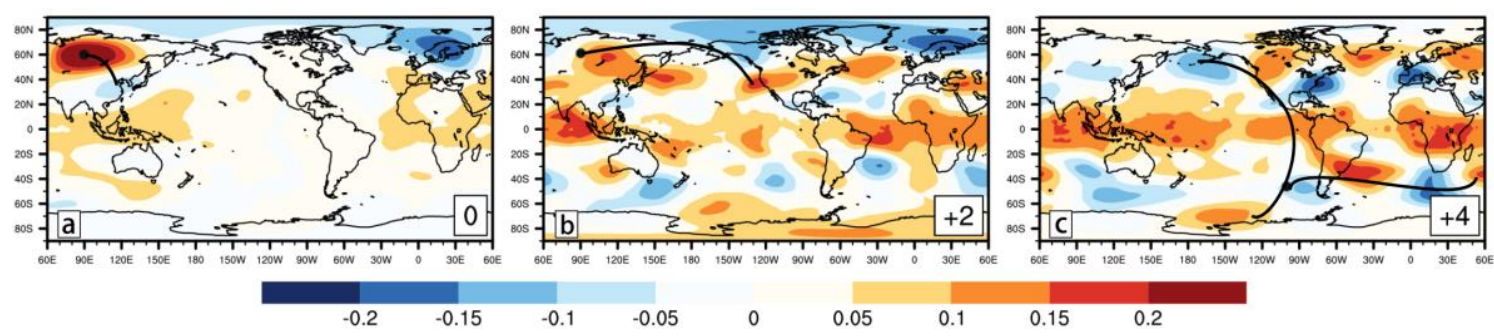

0.05

$0.1 \quad 0.15$

Fig. 7. Lead-lag correlation coefficients between the $300-\mathrm{hPa}$ height anomaly at the basepoint $\left(60^{\circ} \mathrm{N}, 90^{\circ} \mathrm{E}\right)$ and the global field (filling, black dot: the base point and branch point, subscript: month, black curves indicate the wave propagation path). All shading areas exceed $95 \%$ significance level.

When analyzing the changes in wave-activity flux caused by Antarctic ice cover, we will start from June (corresponding to the winter in southern hemisphere). As can be seen from Fig. $\underline{8}$, when we only change the Antarctic ice cover, we can notice that at the first time point, the wave-activity flux changes in the Antarctic and Arctic regions at the same time, although the wave-activity flux changes in the northern hemisphere are not as strong as those in the southern hemisphere. That is to say, after the change of Antarctic ice cover, it got a very rapid response in the northern hemisphere, which is very strange and thought-provoking. The sea-land distribution in the northern and southern hemispheres is very different, and there is more land in the northern hemisphere, so the prevailing westerlies are split and its intensity is weak. In the southern hemisphere, the ocean area accounts for the majority, so the prevailing westerlies are complete and stronger. Changes in ice cover will bring changes in north-south temperature gradients, affecting the location and intensity of the prevailing westerlies. Therefore, in the process of ice cover affecting the climate, the location of ice cover and the westerly jet stream plays an important role, which may be the reason why changes in Antarctic ice cover can quickly affect 
the northern hemisphere. It can be seen from the anomalous spatial distribution of the 300hpa height field (Fig. 9), after the ice cover changes in the Antarctic region, due to the change in temperature gradient, the baroclinicity of the atmosphere changes, and a baroclinic fluctuation rapidly occurs in the southern hemisphere. Over time, the wave passed north and crossed the equator to reach the northern hemisphere. At the same time, it divided into two branches, one of which continued to pass north, and the other spread eastward through the North American region. The entire northward transmission process of the wave is also faster than the wave transmission process when the Arctic ice cover changes.

\section{Baroclinic eddy growth rate}
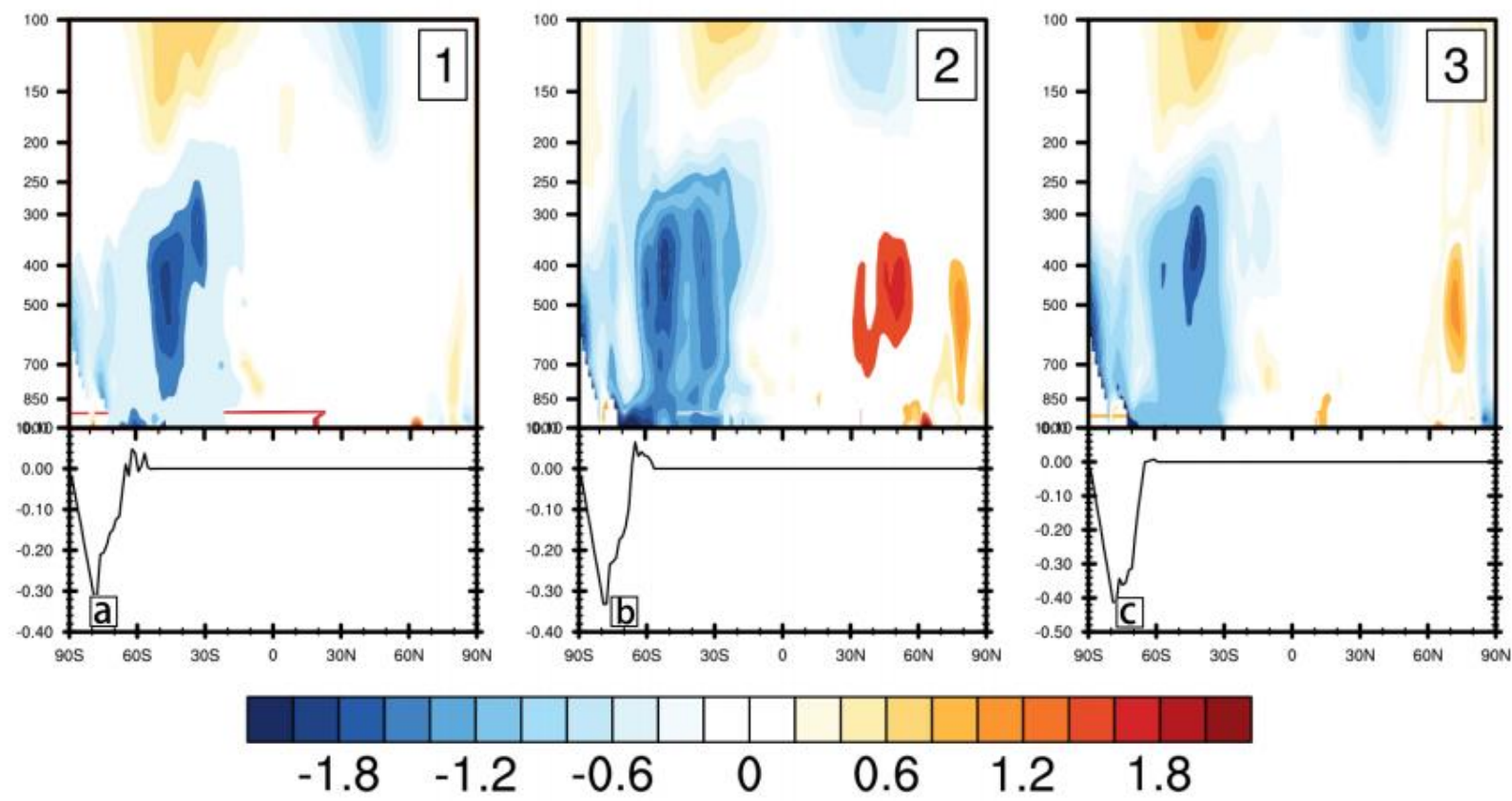

Wave-activity flux
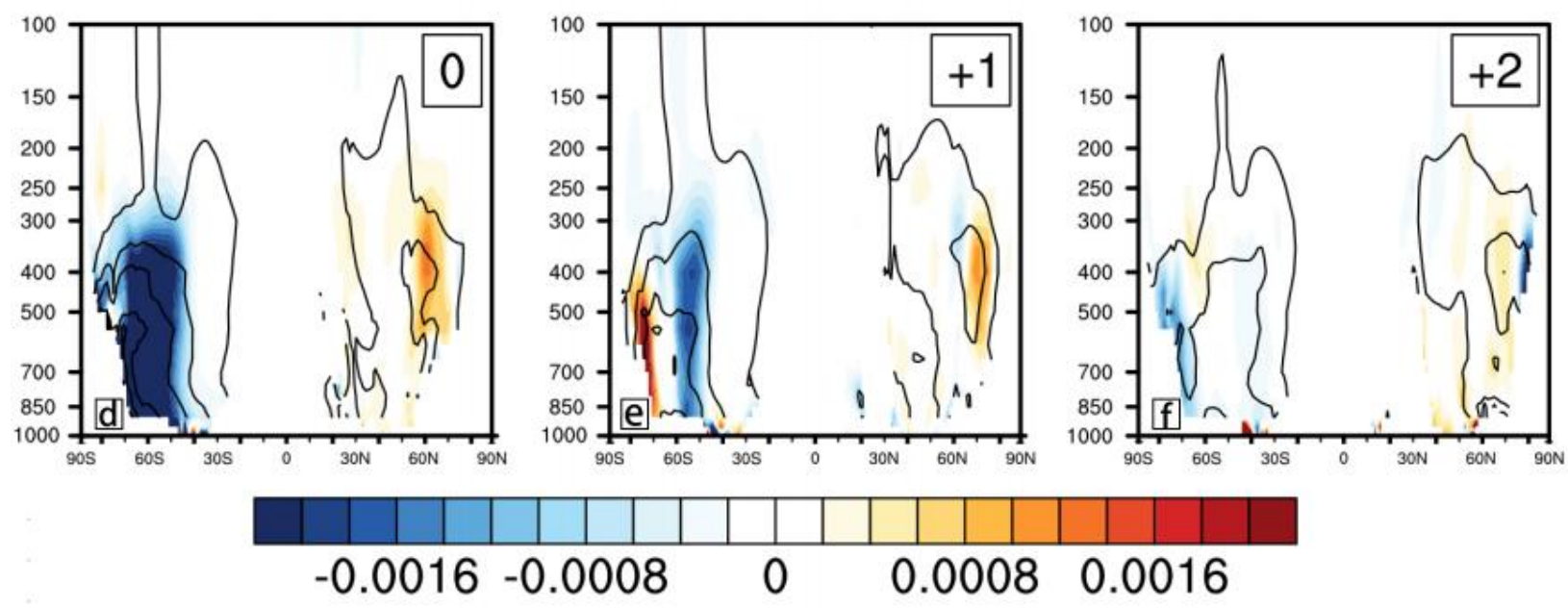
Fig. 8. Vertical section of the difference in meridional mean (a-c) baroclinic growth rate and 456 changes in Antarctic ice cover (d-f) wave-activity flux between CTRL and SSIC (filling, contour 457 line: wave-activity flux distribution in CTRL, polyline: ice cover change with latitude, 458 superscript: month). All shading areas exceed 95\% significance level.
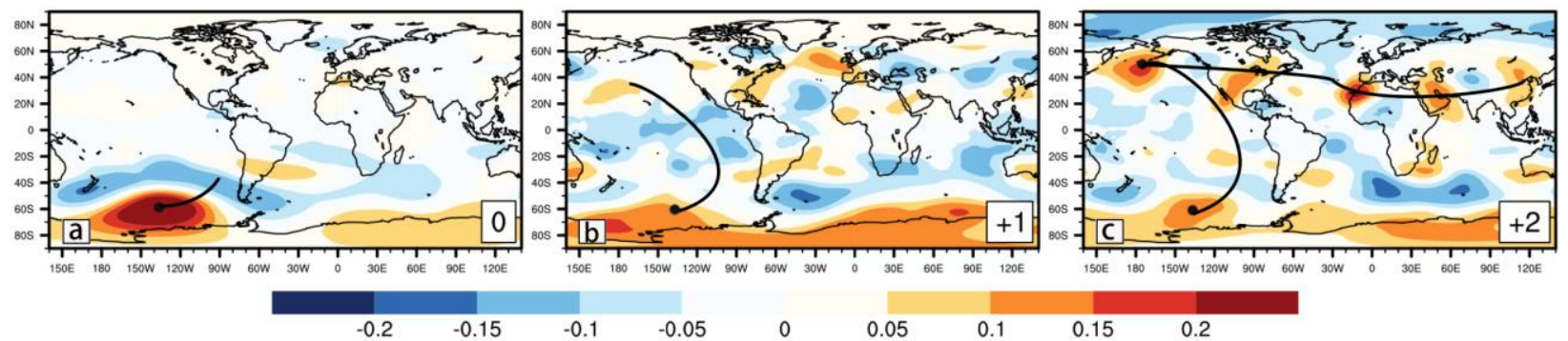

Fig. 9. Lead-lag correlation coefficients between the 300-hPa height anomaly at the basepoint $\left(60^{\circ} \mathrm{S}, 135^{\circ} \mathrm{W}\right)$ and the global field (filling, black dot: the base point and branch point, subscript: month, black curves indicate the wave propagation path) All shading areas exceed 95\% significance level. 


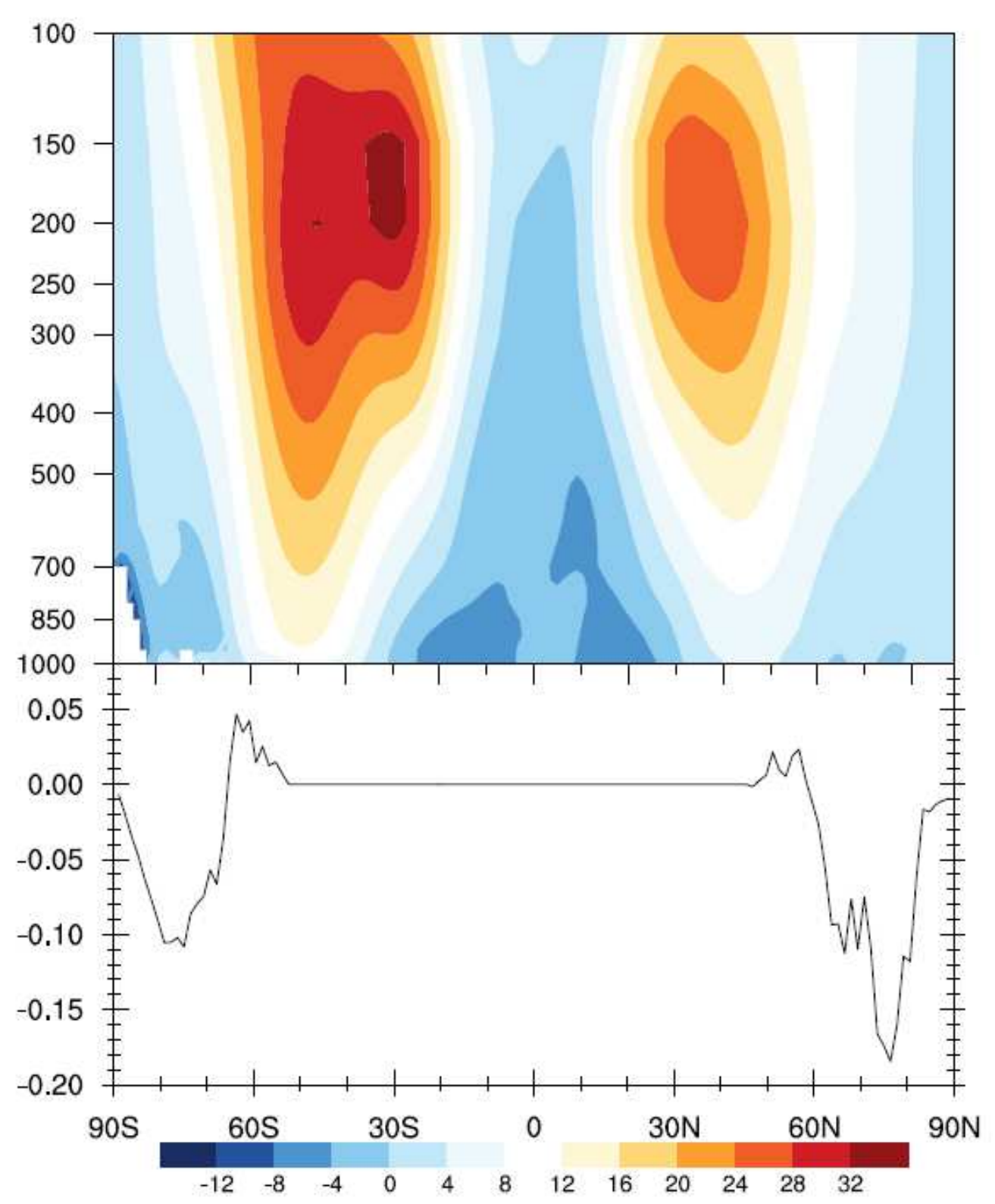

465 Fig. 10. Vertical section of the zonal wind (filling, unit: $\mathrm{m} / \mathrm{s}$ ) and the line chart of ice coverage 466 changes between the year 1965 and 2000 (polyline, unit: fraction).

Due to the difference in the distribution of land and sea, the atmospheric circulation patterns 468 in the northern and southern hemispheres are different. The prevailing westerlies in the southern 469 hemisphere is wider than that in the northern hemisphere, and the upper westerly jet stream is 470 stronger and wider (Fig. 10). Arctic ice cover and Antarctic ice cover are mainly reduced, and 471 marginal ice cover has increased, but Antarctic ice cover has increased more significantly and is 472 closer to the location of upper jets. In other words, changes in Antarctic ice cover have a more 
pronounced effect on the upper jets, which are more closely related to high-altitude westerly jets than Arctic ice cover. Therefore, the location of Antarctic ice cover and the westerly jet may affect the climate effect of Antarctic ice cover. A new set of experiments (SSIC_South_Movement) is added. The change of the ice cover in the SSIC (removing the range of 85 to 90 s) is shifted to the south by 5 degrees, and superimposed on the 2000 Antarctic ice cover of CTRL as the ice cover forced field in the SSIC_South_Movement (Fig. 11), and other settings are consistent with SSIC. The distance between the region of the ice cover change and the atmospheric jets is increased, so the hypothesis of the effect of ice cover on the jet stream mentioned above is examined. In this case, ice cover changes do not correspond to high-altitude jets, that is, the direct effects of ice cover changes on the jets have weakened.

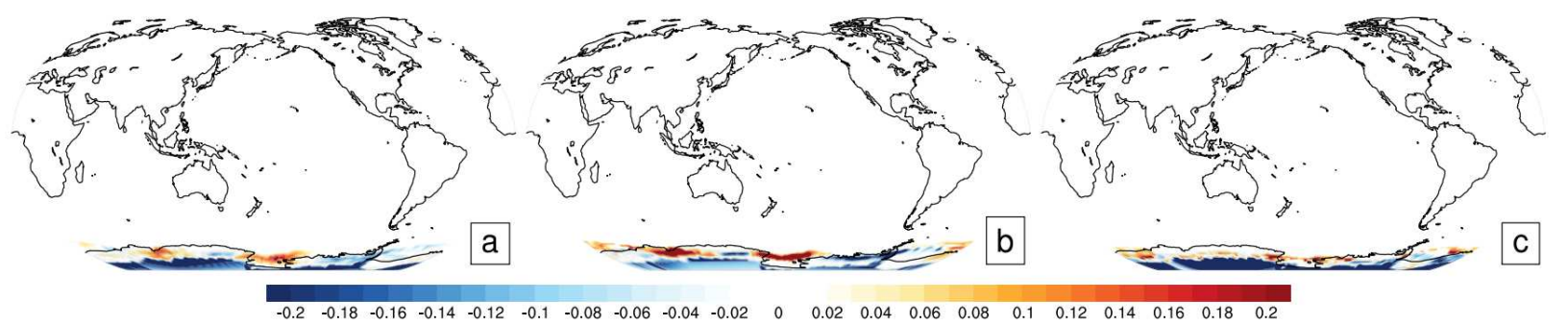

Fig. 11. Change in ice cover forced field between control and SSIC_South_Movement experiments. (a: annual average, b: summer average, c: winter average; filling, unit: fraction)
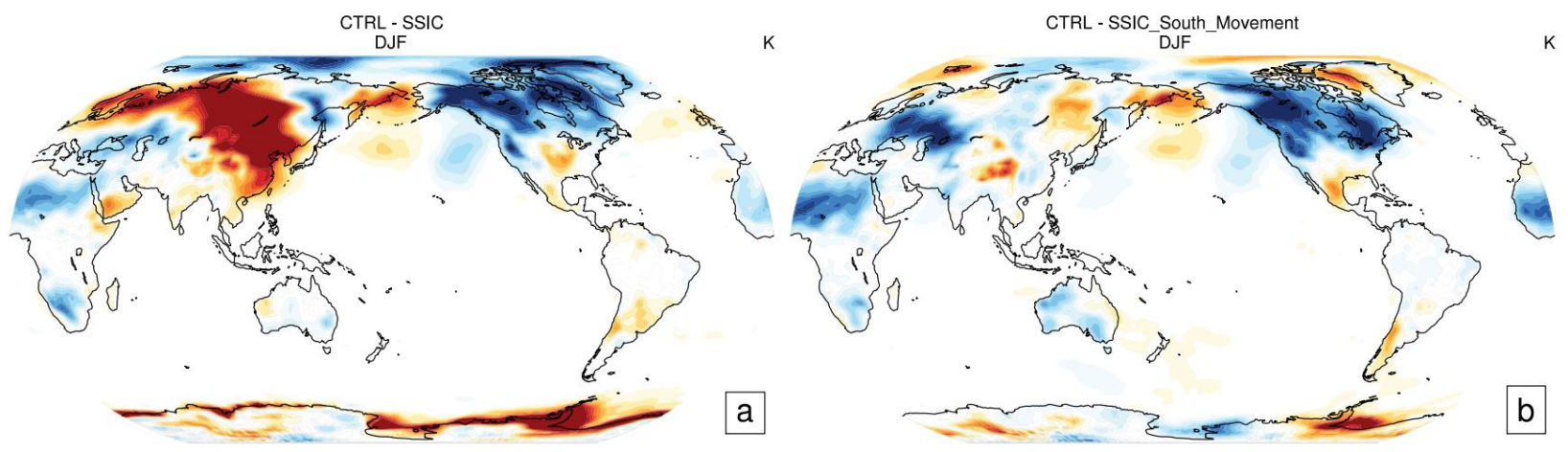

$\begin{array}{llllllllllllllllllllllll}-1 & -0.9 & -0.8 & -0.7 & -0.6 & -0.5 & -0.4 & -0.3 & -0.2 & -0.1 & 0 & 0.1 & 0.2 & 0.3 & 0.4 & 0.5 & 0.6 & 0.7 & 0.8 & 0.9 & 1\end{array}$

Fig. 12. $2 \mathrm{~m}$ temperature anomalies. Difference between control and contrast experiments. (filling, unit: K; a: SSIC, b: SSIC_South_Movement). All shading areas exceed 95\% significance level. 
After shifting the change of Antarctic ice cover in the forcing field 5 latitudes to the south, it

492 can be seen that the temperature response has become significantly weaker. In general, the

493 warming caused by changes in Antarctic ice cover has significantly weakened in East Asia (Fig.

494 12). For North America, the temperature decrease has decreased, including the reduction of the

495 range and the decrease in amplitude. In addition, the magnitude of wave-activity flux changes

496 has also decreased (Fig. 13). It can be seen that after the Antarctic ice cover change field shifted

$4975^{\circ}$ to the south, the response of the wave-activity flux in the southern hemisphere in the earlier

498 period decreased significantly. Therefore, the climate effect also weakened in the SSIC_

499 South_Movement.
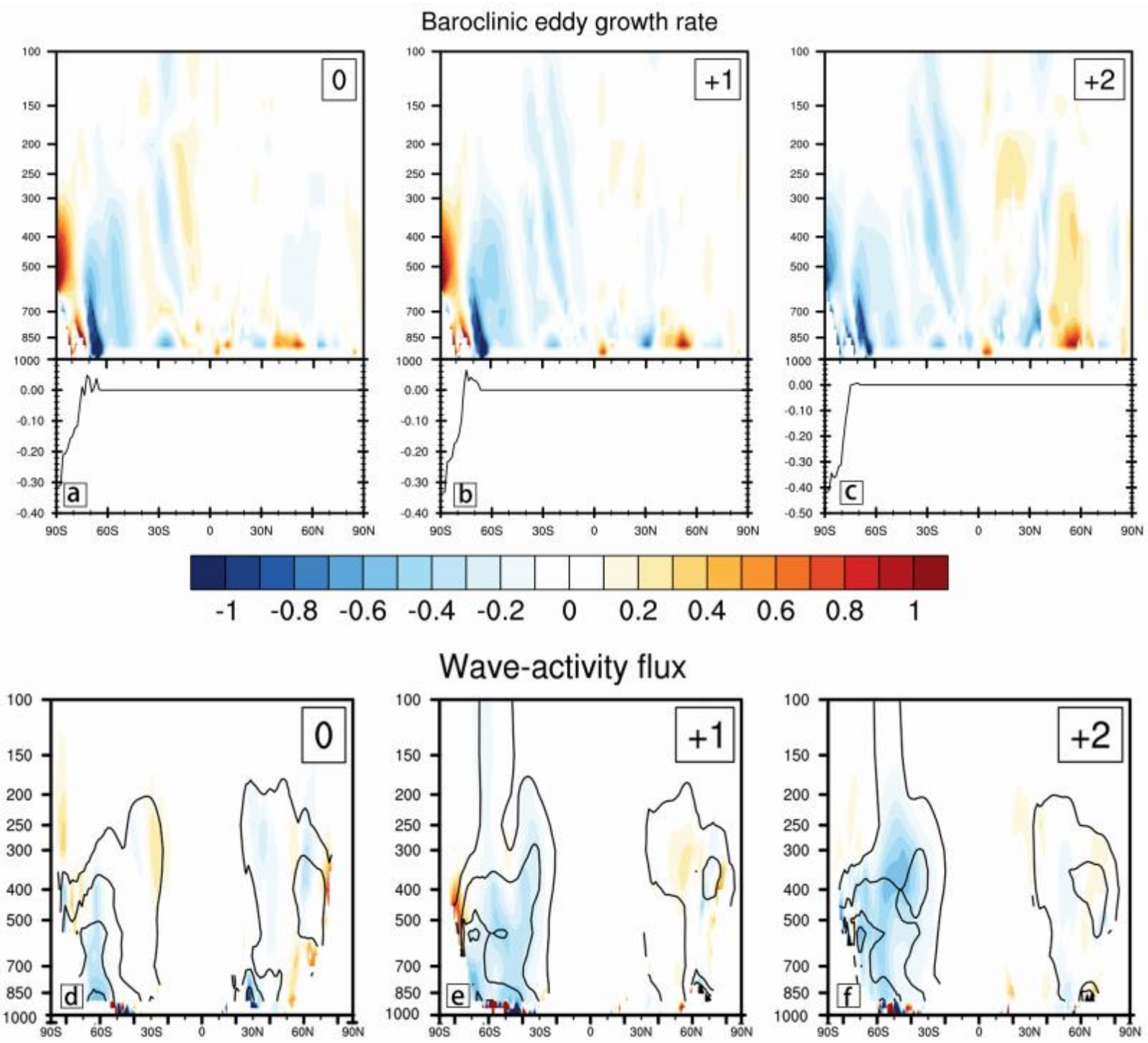

Wave-activity flux
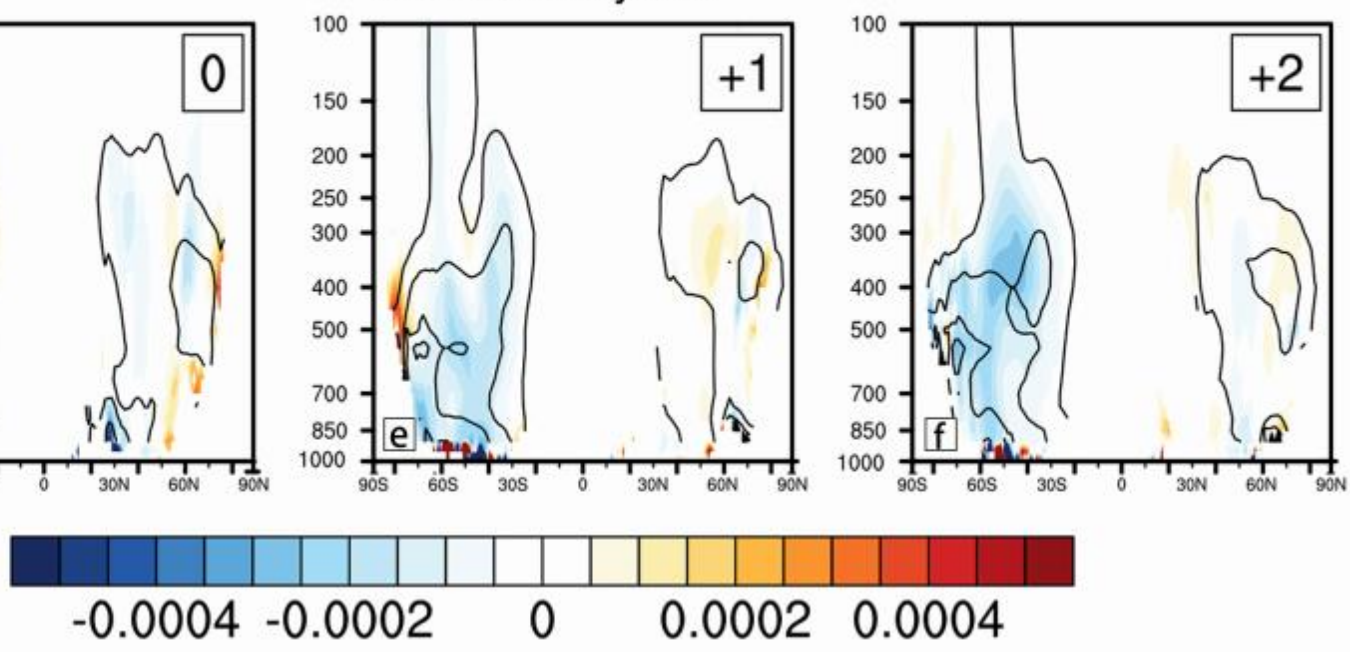
Fig. 13. Vertical section of the difference in meridional mean baroclinic growth rate and waveactivity flux between SSIC and SSIC_South_Movement, changes in Antarctic ice cover in the forced field by month (filling, contour line: wave-activity flux distribution in SSIC, polyline: sea ice change with latitude, superscript: month). All shading areas exceed 95\% significance level.

\section{Summary and discussion}

In previous studies, the influence of Arctic (Antarctic) ice cover on the Northern Hemisphere (Southern Hemisphere) was generally studied (Cattiaux et al., 2010; Raphael et al., 2011, Vihma, 2014). However, this study revealed the trans-equatorial climate effects of the two ice covers and their mechanisms. According to the Liang-Kleeman information flow method, it was found that the information flows from Arctic and Antarctic sea ices to the $2 \mathrm{~m}$ temperature are obvious. Furthermore, the influence of Antarctic sea ice on the temperature in East Asia was greater than that of Arctic sea ice. Previous studies have also shown that changes in Antarctic sea ice will affect the climate of East Asia (Fan and Wang, 2006; Zhu, 2009). However, whether the influence of Antarctic ice cover on the climate of East Asia is greater than that of the Arctic ice cover requires further research.

In order to study the specific temperature changes brought about by the sea ice changes, the observation data-sets were analyzed. Based on the observed sea ice cover data, the years 1987 (in which the Arctic sea ice anomaly increased) and 1990 (in which the Arctic sea ice anomaly decreased) were selected to discuss the different interannual responses of air temperature accompanied with almost no variance in the Antarctic ice cover. Likewise, the years 2003 (Antarctic sea ice anomaly increased) and 2005 (Antarctic sea ice anomaly decreased) were selected as the forcing of the interannual variation of Antarctic sea ice cover. It can be seen that the decrease in Arctic sea ice was accompanied by the warming in most parts of East Asia, cooling in Europe, warming in North America (Canada), and cooling in the South (USA). When the Antarctic sea ice was abnormally decreased, most regions of China had a warming anomaly, while the temperature in Europe decreases. At the same time, the temperature in the south of North America was rising, while in the north part, there was a cooling anomaly. Similarly, this trans-hemispheric forcing relationship of sea ice covers in the Arctic and Antarctic regions could be obtained from the results of the information flow, in which the anomaly of Antarctic ice 
covers had also led to the significant temperature changes in Eurasia and North America. In conclusion, changes in ice covers seemed to produce a trans-equatorial climate effects, affecting the temperature in the other hemisphere, especially the Antarctic ice covers.

In the observation, changes in temperature were simultaneously affected by multiple forcing factors. In order to analysis the mechanism of the cross-equatorial climate effect of ice covers, we conducted multiple sets of numerical experiments. In the results of the CAM4.0 simulations, the temperature anomalies in SSIC simulation (in which only the Antarctic ice cover changed) were closer to that of SIC simulation (changing both Arctic and Antarctic ice cover), which was characterized by an obvious cooling in European winter. However, a warming in East Asia and a cooling in North America in winter was mainly caused by the changes in the Antarctic ice cover. In the simulations, both Arctic and Antarctic ice covers would also affect the other hemisphere across the equator. Studies have shown that Rossby waves can propagate across the equator through the "window area" (Li et al., 2019). Liu et al. (2018) proposed the South-North Pacific (SNP) teleconnection pattern, and proved that SNP can act as an "atmospheric bridge" to propagate wave energy across the equator. In this research we further studied the trans-equatorial climate effect caused by the propagation of wave-activity fluxes. After the change of Arctic (Antarctic) ice covers, the local temperature of the Arctic (Antarctic) with the intensity of atmospheric baroclinicity at mid-high latitudes increased or decreased firstly. As a result, the local baroclinic wave-activity fluxes over the Arctic (Antarctic) changed (Fig.14). As time progresses, the wave energy transmission gradually traveled across the equator in the meridional direction, affecting the climate in the other hemisphere. However, the climatological prevailing mid-latitude westerly jet in the southern hemisphere were stronger and wider than that in the northern hemisphere, which was also closer to the edge of ice cover. The intensity of the transequatorial climate effect caused by the Antarctic ice cover was much stronger than that by Arctic ice changing. In order to verify the relationship between the trans-equatorial climate effect and the position of ice cover, a set of experiment with shifting the Antarctic ice cover by five latitudes southwardly was made, which performed a much weakened locally forcing on the southern hemisphere and no trans-equatorial effect.

In general, compared with the Arctic ice cover, the Antarctic ice cover was closer to the mid-latitude westerly jet, and the intensity of the jet was stronger in the southern hemisphere. Therefore, the Antarctic ice cover caused more significant changes in the upper atmospheric 
562 height field and jet stream by changing the low-level atmospheric temperature gradient and the 563 process of atmospheric baroclinic wave uploading. The stronger height field anomaly in the 564 southern hemisphere then caused the obvious Rossby fluctuation anomaly propagation across the 565 equator, leading to significant temperature changes in the northern hemisphere, especially over 566 the Eurasia and North America. In the Liang-Kleeman information flow and numerical model 567 results, the trans-equatorial effects of the Antarctic ice cover on the northern hemisphere were 568 even more significant than the effects of the Arctic ice cover, which indicated that the variation 569 of Antarctic ice cover was indispensable in the medium- and long-term weather and climate 570 prediction of the northern hemisphere. 

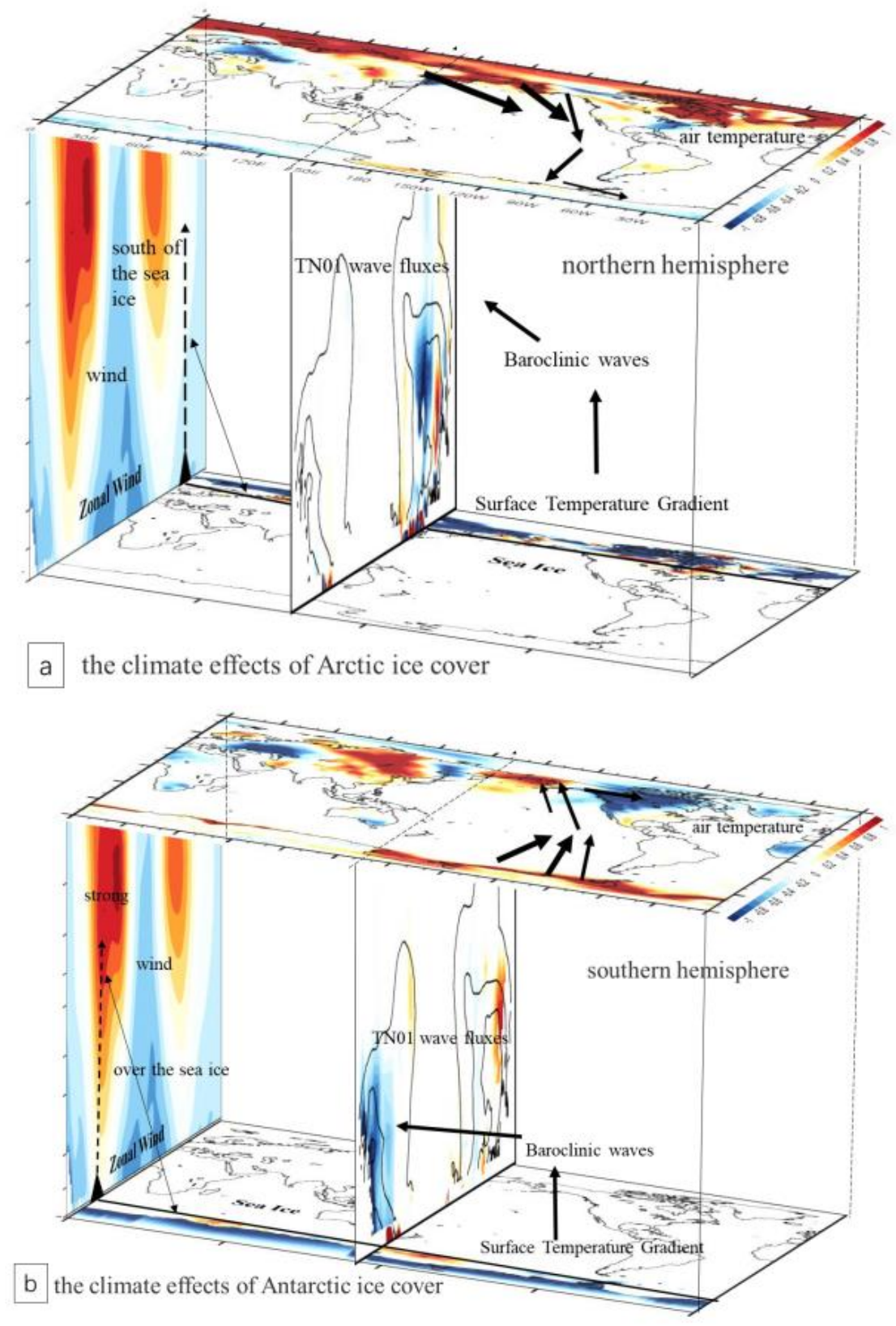

572 Figure 14. The conceptual map of the climate effects of ice cover (a) Arctic ice cover (b) 573 Antarctic ice cover

\section{Acknowledgements}

This work was supported by the National Key Program for Developing Basic Science

577 (grants 2016YFA0600303 and 2018YFC1505902), the National Natural Science Foundation of 
China (grants 41330420, 41621005, 41675064, 41675067, and 41875086), the Jiangsu Province Science Foundation (Grant No. BK20201259). The authors are thankful for the support of the Jiangsu Provincial Innovation Center for Climate Change and Fundamental Research Funds for the Central University. This work was jointly supported by the Joint Open Project of KLME and CIC-FEMD (grant KLME201902). The sea ice data used in this paper are the OISST monthly data of NOAA (https://www.esrl.noaa.gov/psd/data/gridded/data.noaa.oisst.v2.html). The temperature data is monthly surface temperature from NCEP/NCAR (https://www.esrl.noaa.gov/psd/data/gridded/data.ncep.reanalysis.surface.html).

\section{References}

Alekseev G., Glok N., Vyazilova A., et al. (2017) Influence of SST in the equatorial North Atlantic on warming and sea ice shrinking in the Arctic. EGU General Assembly Conference. EGU General Assembly Conference Abstracts, 2017.

Allison I., Barry R. G., Barry E. Goodison (2001) Climate and Cryosphere (CliC) Project. World climate research programme, Science and co-ordination plan, Version 1, WCRP Report.

Blackport R., Kushner P J. (2017) Isolating the Atmospheric Circulation Response to Arctic Sea Ice Loss in the Coupled Climate System. Journal of Climate, 30(6), 2163-2185. https://doi.org/10.1175/JCLI-D-16-0257.1

Caian M., Torben Köenigk, Ralf Döscher, et al. (2017) An interannual link between Arctic seaice cover and the North Atlantic Oscillation. Climate Dynamics, 50(443). https://doi.org/10.1007/s00382-017-3684-Z

Cattiaux, J., Vautard, R., Cassou, C., Yiou, P., Masson-Delmotte, V., \& Codron, F. (2010) Winter 2010 in Europe: A cold extreme in a warming climate. Geophysical Research Letters, 37(20). https://doi.org/10.1029/2010gl044613

Cavalieri D. J., Gloersen P., Parkinson C. L., Comiso J. C., Zwally H. J. (1997) Observed hemispheric asymmetry in global sea ice changes. Science, 278: 1104-1106. https://doi.org/10.1126/science.278.5340.1104

Cavalieri D. J., Parkinson C. L. (2008) Antarctic sea ice variability and trends, 1979-2006. Journal of Geophysical Research Oceans, 113(C7). https://doi.org/10.1029/2007JC004564 
Cavalieri, D. J., Gloersen, P., Parkinson, C. L., Comiso, J. C., \& Zwally, H. J. (1997) Observed hemispheric asymmetry in global sea ice changes. Science, 278(5340), 1104-1106. https://doi.org/10.1126/science.278.5340.1104

Cavalieri, D. J., Parkinson, C. L., \& Vinnikov, K. Y. (2003) 30-year satellite record reveals contrasting arctic and Antarctic decadal sea ice variability. Geophysical Research Letters, 30(18), 1970-0. https://doi.org/10.1029/2003GL018031

Cavalieri, D. J., Parkinson, C. L., \& Vinnikov, K. Y. (2003) 30-year satellite record reveals contrasting arctic and Antarctic decadal sea ice variability. Geophysical Research Letters, 30(18). https://doi.org/10.1029/2003GL018031

Cavalieri, D. J., Parkinson, C. L., Gloersen, P., Comiso, J. C., \& Zwally, H. J. (1999) Deriving long-term time series of sea ice cover from satellite passive-microwave multisensory data sets. Journal of Geophysical Research: Oceans, 104(C7), 15803-15814. https://doi.org/10.1029/1999JC900081

Chen, F. F., Chen, Q., Hu, H., Fang, J., \& Bai, H. (2020) Synergistic Effects of Midlatitude Atmospheric Upstream Disturbances and Oceanic Subtropical Front Intensity Variability on Western Pacific Jet Stream in Winter. Journal of Geophysical Research: Atmospheres, 125(17). https://doi.org/10.1029/2020jd032788

Chen, F., Hu, H., \& Bai, H. (2020) Subseasonal coupling between subsurface subtropical front and overlying atmosphere in North pacific in winter. Dynamics of Atmospheres and Oceans, 90. https://doi.org/10.1016/j.dynatmoce.2020.101145

Chen, H., Zhang, Y., Yu, M. et al. (2016) Large-scale urbanization effects on eastern Asian summer monsoon circulation and climate. Climate Dynamic 47, 117-136. https://doi.org/10.1007/s00382-015-2827-3

Cheung, H. H. N., Keenlyside, N., Omrani, N. E., \& Zhou, W. (2018) Remarkable link between projected uncertainties of arctic sea-ice decline and winter Eurasian climate. Advances in Atmospheric Sciences, 35(1), 38-51. https://doi.org/10.1007/s00376-017-7156-5

Christopher, R., Godfred-Spenning, Ian, Simmonds. (1996). An analysis of Antarctic sea-ice and extratropical cyclone associations. International Journal of Climatology, 16(12), 13151332. https://doi.org/10.1002/(SICI)1097-0088(199612)16:12<1315::AIDJOC92>3.0.CO;2-M 
Claire, L., \& Parkinson. (1991) Interannual variability of the spatial distribution of sea ice in the north polar region. Journal of Geophysical Research, 96(C3), 4791-4801. https://doi.org/10.1029/91JC00082

Comiso J. C., Nishio F. (2008) Trends in the sea ice cover using enhanced and compatible AMSR-E, SSM/I, and SMMR data. Journal of Geophysical Research Oceans, 113(C02S07). https://doi.org/10.1029/2007JC004257

Comiso J. C., Parkinson C L, Gersten R., et al. (2008) Accelerated decline in the Arctic sea ice cover. Geophysical Research Letters, 35(1): L01703. https://doi.org/10.1029/2007GL031972

De Magalhães Neto, N., Evangelista, H., Tanizaki-Fonseca, K. et al. (2012) A multivariate analysis of Antarctic sea ice since 1979. Climate Dynamics 38, 1115-1128. https://doi.org/10.1007/s00382-011-1162-6

Deser C., Walsh J. E., Timlin M. S. (2000) Arctic Sea Ice Variability in the Context of Recent Atmospheric Circulation Trends. Journal of Climate, 13(3):617-633. https://doi.org/10.1175/1520-0442(2000)013<0617:ASIVIT>2.0.CO;2

Elizabeth A. B. (2013) Revisiting the evidence linking Arctic amplification to extreme weather in midlatitudes. Geophysical Research Letters,40(17). https://doi.org/10.1002/grl.50880

Fan, K., Wang, H. (2006) Interannual variability of Antarctic Oscillation and its influence on East Asian climate during boreal winter and spring. Science in China Series D, 49, 554560. https://doi.org/10.1007/s11430-006-0554-7

Fan, T., Deser, C., \& Schneider, D. P. (2014) Recent Antarctic sea ice trends in the context of Southern Ocean surface climate variations since 1950. Geophysical Research Letters, 41(7):2419-2426. https://doi.org/10.1002/2014GL059239

Francis J. A., Hunter E. (2006) New insight into the disappearing Arctic sea ice. Eos, Transactions American Geophysical Union, 87(46):509-524. https://doi.org/10.1029/2006EO460001

Francis, J. A., \& Vavrus, S. J. (2012) Evidence linking arctic amplification to extreme weather in mid-latitudes. Geophysical Research Letters, 39(6). https://doi.org/10.1029/2012GL051000 
Francis, J. A., Chan, W., Leathers, D. J., Miller, J. R., \& Veron, D. E. (2009) Winter northern hemisphere weather patterns remember summer arctic sea-ice extent. Geophysical Research Letters, 36(7). https://doi.org/10.1029/2009gl037274

Gao, Y., Sun, J., Li, F., He, S., Sandven, S., \& Yan, Q., et al. (2015) Arctic sea ice and eurasian climate: a review. Advances in Atmospheric Sciences, 32(01):92-114. https://doi.org/10.1007/s00376-014-0009-6

Gent P. R., Danabasoglu G., Donner L. J., et al. (2011) The community climate system model version 4. Journal of Climate, 24: 4973-4991. https://doi.org/10.1175/2011JCLI4083.1

Gloersen, P. Modulation of hemispheric sea-ice cover by ENSO events. (1995) Nature 373, $503-$ 506. https://doi.org/10.1038/373503a0

Gloersen, P., \& Campbell, W. J. (1991) Recent variations in Arctic and Antarctic sea-ice covers. Nature, 352(6330), 33-36. https://doi.org/10.1038/352033a0

Gloersen, P., Campbell, W.J., Cavalieri, D.J., Comiso, J.C., Parkinson, C.L., Zwally, H.J. (1992) Arctic and Antarctic sea ice, 1978-1987: satellite passive-microwave observations and analysis. NASA S-511, 57. https://doi.org/10.1016/0021-9169(95)90010-1

Hegyi, B.M. and Taylor, P.C. (2018) The Unprecedented 2016-2017 Arctic Sea Ice Growth Season: The Crucial Role of Atmospheric Rivers and Longwave Fluxes. Geophysical Research Letters, 45, 5204-5212. https://doi.org/10.1029/2017GL076717

Herman G. F., Johnson W. T. (1978) The Sensitivity of the General Circulation to Arctic Sea Ice Boundaries: A Numerical Experiment. Monthly Weather Review, 106(12):1649-1664. http://dx.doi.org/10.1175/1520-0493(1978)106<1649:TSOTGC>2.0.CO;2

Higgins M. E., Cassano J. J. (2009) Impacts of reduced sea ice on winter Arctic atmospheric circulation, precipitation, and temperature. Journal of Geophysical Research: Atmospheres, 114. https://doi.org/10.1029/2009JD011884

Horel, J. D., \& Wallace, J. M. (1981) Planetary-scale atmospheric phenomena associated with the southern oscillation. Monthly Weather Review, 109(4), 813-829. https://doi.org/10.1175/1520-0493(1981)109<0813:PSAPAW>2.0.CO;2

Hoskins, B. J., \& Valdes, P. J. (1990) On the existence of storm-tracks. Journal of the Atmospheric Sciences, 47(15), 1854-1864. https://doi.org/10.1175/1520$\underline{0469(1990) 047<1854: \text { OTEOST }>2.0 . C O ; 2}$ 
James, A., Screen, Ian, Simmonds. (2010) The central role of diminishing sea ice in recent Arctic temperature amplification. Nature, 464(7293):1334-7. https://doi.org/10.1038/nature09051

Jiang, S., Hu, H., Zhang, N. et al. (2019) Multi-source forcing effects analysis using LiangKleeman information flow method and the community atmosphere model (CAM4.0). Climate Dynamic 53, 6035-6053. https://doi.org/10.1007/s00382-019-04914-x

Jie, S. , Wen, Z. , Li, C. , \& Qi, L. . (2009). Signature of the antarctic oscillation in the northern hemisphere. Meteorology \& Atmospheric Physics, 105(1-2), 55-67. https://doi.org/10.1007/s00703-009-0036-5

Journal of Physical Oceanography, 9(3), 580-591. https://doi.org/10.1175/15200485(1979)009<0580:AAOASI>2.0.CO;2

Kay J. E., Gettelman, A. (2009) Cloud influence on and response to seasonal arctic sea ice loss. Journal of Geophysical Research Atmospheres, 114(D18). https://doi.org/10.1029/2009JD011773

Kim, K. Y., Hamlington, B. D., Na, H., \& Kim, J. (2016) Mechanism of seasonal arctic sea ice evolution and arctic amplification. The Cryosphere, 10(5), 2191-2202. https://doi.org/10.5194/tc-10-2191-2016

King J. C., Turner J. (1997) Antarctic Meteorology and Climatology. Cambridge University Press, 1997.

Kolstad E. W., Bracegirdle T. J. (2008) Marine cold-air outbreaks in the future: an assessment of IPCC AR4 model results for the Northern Hemisphere. Climate Dynamics, 30(7-8):871885. https://doi.org/10.1007/s00382-007-0331-0

Kwok, R., \& Comiso, J. C. (2002). Southern Ocean climate and sea ice anomalies associated with the southern oscillation. Journal of Climate, 15(5), 487-487.

Li, Y., Feng, J., Li, J., \& Hu, A. (2019) Equatorial windows and barriers for stationary rossby wave propagation. Journal of Climate, 32(18). https://doi.org/10.1175/JCLI-D-18-0722.1

Liang X.S. (2013) Local predictability and information flow in complex dynamical systems. Physical D Nonlinear Phenomena 248:1-15. https://doi.org/10.1016/j.physd.2012.12.011

Liang X.S. (2014) Unraveling the cause-effect relation between time series. Physical Review E Stat Nonlinear Soft Matter Phys, 90(5-1):052150. https://doi.org/10.1103/PhysRevE.90.052150 
Liang X.S. (2015) Normalizing the causality between time series. Physical Review E, 92(2):022126. https://doi.org/10.1103/PhysRevE.92.022126

Liang X.S. (2018) Causation and information flow with respect to relative entropy. Chaos, 28(7):075311. https://doi.org/10.1063/1.5010253

Liang, X. S. (2016). Information flow and causality as rigorous notions ab initio. Physical Review E, 94(5), 052201, 1-28. https://doi.org/10.1103/PhysRevE.94.052201

Lima, N. E. D., \& Ambrizzi, T. (2002) The influence of atmospheric blocking on the Rossby wave propagation in southern hemisphere winter flows. Journal of the Meteorological Society of Japan.ser.ii, 80(2), 139-159. https://doi.org/10.2151/jmsj.80.139

Lindsay, R. W., \& Zhang, J. (2004) The thinning of arctic sea ice, 1988 2003: have we passed a tipping point? Journal of Climate, 18(22), 4879-4894. https://doi.org/10.1175/JCLI3587.1

Liu A. Q., Moore G. W. K., Tsuboki K., et al. (2006) The Effect of the Sea-ice Zone on the Development of Boundary-layer Roll Clouds During Cold Air Outbreaks. BoundaryLayer Meteorology, 118(3):557-581. https://doi.org/10.1007/s10546-005-6434-4

Liu X., Yin Z. Y. (2001) Spatial and Temporal Variation of Summer Precipitation over the Eastern Tibetan Plateau and the North Atlantic Oscillation. Journal of Climate, 14(13):2896-2909._ http://dx.doi.org/10.1175/15200442(2001)014<2896:SATVOS>2.0.CO;2

Liu, J., Curry, J. A., \& Martinson, D. G. (2004) Interpretation of recent Antarctic sea ice variability. Geophysical Research Letters, 31(2), 2205. https://doi.org/10.1029/2003GL018732

Liu, J., Song, M., Horton, R. M., \& Hu, Y. (2013) Reducing spread in climate model projections of a September ice-free Arctic. Proceedings of the National Academy of Sciences of the United States of America, 110(31), 12571-12576. https://doi.org/10.1073/pnas.1219716110

Liu, T., Li, J., Li, Y. et al. (2018) Influence of the May Southern annular mode on the South China Sea summer monsoon. Climate Dynamics, 51, 4095-4107. https://doi.org/10.1007/s00382-017-3753-3

Liu, W., \& Fedorov, A. V. (2019). Global impacts of Arctic sea ice loss mediated by the Atlantic meridional overturning circulation. Geophysical Research Letters, 46, 944- 952. https://doi.org/10.1029/2018GL080602 
Manabe, S., \& Stouffer, R. J. (1994) Multiple-century response of a coupled ocean-atmosphere model to an increase of atmospheric carbon dioxide. Journal of Climate, 7(1), 5-23. https://doi.org/10.1175/1520-0442(1994)007<0005:MCROAC>2.0.CO;2

Mare, W. (1997) Abrupt mid-twentieth-century decline in Antarctic sea-ice extent from whaling records. Nature, 389, 57-60. https://doi.org/10.1038/37956

Martinson, \& Douglas, G. (2003). Spatial/temporal patterns in weddell gyre characteristics and their relationship to global climate. Journal of Geophysical Research Oceans, 108(C4). https://doi.org/10.1029/2000JC000538

Meehl G. A., Arblaster J. M., Jr W. G. S. (2000) Sea-ice effects on climate model sensitivity and low frequency variability. Climate Dynamics, 16(4):257-271. https://doi.org/10.1007/s003820050326

Mokhov, I. I., \& Parfenova, M. R. (2021). Relationship of the extent of antarctic and arctic ice with temperature changes, 1979-2020. Doklady Earth Sciences, 496(1), 66-71. https://doi.org/10.1134/S1028334X21010153

Nakamura T., Yamazaki K., Iwamoto K., et al. (2015) A negative phase shift of the winter $\mathrm{AO} / \mathrm{NAO}$ due to the recent Arctic sea-ice reduction in late autumn. Journal of Geophysical Research: Atmospheres, 120(8):3209-3227. https://doi.org/10.1002/2014JD022848

Nakamura, M., Kadota, M., \& Yamane, S. (2010) Quasigeostrophic Transient Wave Activity Flux: Updated Climatology and Its Role in Polar Vortex Anomalies, Journal of the Atmospheric Sciences, 67(10), 3164-3189. https://doi.org/10.1175/2010JAS3451.1

Neale R. B., Richter J. H., Conley A. J., et al. (2010) Description of the NCAR Community Atmosphere Model (CAM 4.0). Technical Note NCAR/TN-485+STR. 2010.

Neale R. B., Richter J. H., Jochum M. (2008) The Impact of Convection on ENSO: From a Delayed Oscillator to a Series of Events. Journal of Climate, 21(22):5904-5924. https://doi.org/10.1175/2008JCLI2244.1

Neale, R. B., Richter, J., Park, S., Lauritzen, P. H., Vavrus, S. J., \& Rasch, P. J., et al. (2013) The mean climate of the community atmosphere model (cam4) in forced sst and fully coupled experiments. Journal of Climate, 26(14), 5150-5168. https://doi.org/10.1175/JCLI-D-12$\underline{00236.1}$ 
795

Nghiem, S. V., Rigor, I. G., Perovich, D. K., P. Clemente-Colón, Weatherly, J. W., \& Neumann, G. (2007) Rapid reduction of arctic perennial sea ice. Geophysical Research Letters, 34(19). https://doi.org/10.1029/2007GL031138

Niranjan Kumar, K., Ouarda, T.B.M.J., Sandeep, S. et al. (2016) Wintertime precipitation variability over the Arabian Peninsula and its relationship with ENSO in the CAM4 simulations. Climate Dynamic 47, 2443-2454. https://doi.org/10.1007/s00382-016-2973$\underline{2}$

Oleson K. W., Lawrence D. M., Bonan G. B., et al. (2010) Technical Description of version 4.0 of the Community Land Model (CLM). NCAR Technical Note NCAR/TN-478+STR. 2010. https://doi.org/10.1029/2010GL042430

Overland, J. E., Turet, P., \& Oort, A. H. (1996) Regional variations of moist static energy flux into the arctic. Journal of Climate, 9(1), 54-65. https://doi.org/10.1175/15200442(1996)009<0054:RVOMSE >2.0.CO;2

Palm, S. P., Strey, S. T., Spinhirne, J., \& Markus, T. (2010) Influence of arctic sea ice extent on polar cloud fraction and vertical structure and implications for regional climate. Journal of Geophysical Research: Atmospheres, 115(D21). https://doi.org/10.1029/2010JD013900

Parkinson, C. L., \& Cavalieri, D. J. (1989) Arctic sea ice 1973-1987 - seasonal, regional, and interannual variability. Journal of Geophysical Research Oceans, 94(C10), 14499-14523. https://doi.org/10.1029/JC094iC10p14499

Parkinson, C. L., Cavalieri, D. J., Gloersen, P., Zwally, H. J., \& Comiso, J. C. (1999) Arctic sea ice extents, areas, and trends, 1978-1996. Journal of Geophysical Research Oceans, 104(C9), 20837-20856. https://doi.org/10.1029/1999JC900082

Pérez González, M.E., García Rodríguez, M.P. (2014) Evolution in sea ice from 1978 to 2012. Environ Earth Sci 72, 3467-3477. https://doi.org/10.1007/s12665-014-3254-1

Perovich D. K., Richter-Menge J. A., Jones K. F., et al. (2008) Sunlight, water, and ice: Extreme Arctic sea ice melt during the summer of 2007. Geophysical Research Letters, 35(11): L11501. https://doi.org/10.1029/2008GL034007

Qin, D., Zhou, B. \& Xiao, C. (2014) Progress in studies of cryospheric changes and their impacts on climate of China. Journal of Meteorological Research, 28, 732-746. https://doi.org/10.1007/s13351-014-4029-Z 
Raphael, M. N., Hobbs, W., \& Wainer, I. (2011) The effect of Antarctic sea ice on the southern hemisphere atmosphere during the southern summer. Climate Dynamics, 36(7-8), 14031417. https://doi.org/10.1007/s00382-010-0892-1

Raymond D. J., Blyth A. M. (1986) A Stochastic Mixing Model for Nonprecipitating Cumulus Clouds. Journal of the Atmospheric Sciences, 43(22):2708-2718. https://doi.org/10.1175/1520-0469(1986)043<2708:ASMMFN>2.0.CO;2

Raymond D. J., Blyth A. M. (1992) Extension of the Stochastic Mixing Model to Cumulonimbus Clouds. Journal of the Atmospheric Sciences, 49(21):1968-1983. https://doi.org/10.1175/1520-0469(1992)0492.0.CO;2

Richter J. H., Rasch P. J. (2008) Effects of Convective Momentum Transport on the Atmospheric Circulation in the Community Atmosphere Model, Version 3. Journal of Climate, 21(21):1487-1499. https://doi.org/10.1175/2007JCLI1789.1

Rind, D., Healy, R., Parkinson, C., \& Martinson, D. (1995) The role of sea ice in $2 \times c 02$ climate model sensitivity. part i: the total influence of sea ice thickness and extent. Journal of Climate, 8(3), 449-463. https://doi.org/10.1175/1520-0442(1995)0082.0.CO;2

Rogers J. C., Van Loon H. (1979) The Seesaw in Winter Temperatures between Greenland and Northern Europe. Part II: Some Oceanic and Atmospheric Effects in Middle and High Latitudes. Monthly Weather Review, 107(5):509. http://dx.doi.org/10.1175/15200493(1979)107<1095:TSIWTB>2.0.CO;2

Rogers, Jefery, C., Van, Loon, \& Harry. (1979) The seesaw in winter temperatures between Greenland and northern Europe. part ii: some oceanic and atmospheric effects in middle and high latitudes. Monthly Weather Review, 107(9), 1095. https://doi.org/10.1175/15200493(1979)107<1095:TSIWTB>2.0.CO;2

Saba, J. L., Zwally, H., Yi, D., \& Laxon, S. (2004) Mapping Arctic Sea-Ice Freeboard-Height Distributions and Ice Thicknesses With ICESat. American Geophysical Union.

Schiavon S., Zecchin R. (2007) Climate Change 2007: The Physical Science Basis. 92(1):86-87. https://doi.org/10.1080/03736245.2010.480842

Scientific Committee on Antarctic Research. (1993) The role of the Antarctic in global change: an international plan for a regional research programme. Scientific Committee on Antarctic Research. 
Screen, J. A., Simmonds, I. (2010) The central role of diminishing sea ice in recent Arctic temperature amplification. Nature, 464, 1334-1337. https://doi.org/10.1038/nature09051

Screen, J. A., Simmonds, I., \& Keay, K. (2011) Dramatic interannual changes of perennial arctic sea ice linked to abnormal summer storm activity. Journal of Geophysical Research Atmospheres, 116(D15). https://doi.org/10.1029/2011JD015847

Simmonds, I., \& Jacka, T. H. (1995) Relationships between the interannual variability of Antarctic sea ice and the southern oscillation. Journal of Climate, 8(3), 637-647. https://doi.org/10.1175/1520-0442(1995)008<0637:RBTIVO>2.0.CO;2

Solomon, S, Qin, D, Manning, M, Chen, Z, \& Marquis, M. (2007). IPCC 2007: climate change 2007: the physical science basis. contribution of working group to the fourth assessment report of the intergovernmental panel on climate change, 18(2), 95-123. https://doi.org/10.1016/S0925-7721(01)00003-7

Stammerjohn S., Massom R., Rind D., et al. (2012) Regions of rapid sea ice change: An interhemispheric seasonal comparison. Geophysical Research Letters, 39(6). https://doi.org/10.1029/2012GL050874

Stammerjohn, S., Massom, R., Rind, D., \& Martinson, D. (2012) Regions of rapid sea ice change: an inter-hemispheric seasonal comparison. Geophysical Research Letters, 39(6), L06501. https://doi.org/10.1029/2012g1050874

Stips A., Macias D., Coughlan C., Garciagorriz E., Liang X. S. (2016) On the causal structure between CO2 and global temperature. Sci Rep 6:21691. https://doi.org/ $\underline{10.1038 / \text { srep21691 }}$

Stroeve, J., Serreze, M., Drobot, S., Gearheard, S., Holland, M., \& Maslanik, J., et al. (2008) Arctic sea ice extent plummets in 2007. Eos Transactions American Geophysical Union, 89(2). https://doi.org/10.1029/2008EO020001

Takaya K., Nakamura H. (1997) A formulation of a wave-activity flux for stationary Rossby waves on a zonally varying basic flow. Geophysical Research Letters, 24(23):2985-2988. https://doi.org/10.1029/97GL03094

Takaya K., Nakamura H. (2001) A Formulation of a Phase-Independent Wave-Activity Flux for Stationary and Migratory Quasigeostrophic Eddies on a Zonally Varying Basic Flow. Journal of the Atmospheric Sciences, 58(6):608-627. http://dx.doi.org/10.1175/15200469(2001)058<0608:AFOAPI>2.0.CO;2 
Thompson, D. W. J., \& Wallace, J. M. (1998) The arctic oscillation signature in the wintertime geopotential height and temperature fields. Geophysical Research Letters, 25(9), 12971300. https://doi.org/10.1029/98GL00950

Vihma, T. (2014) Effects of Arctic Sea Ice Decline on Weather and Climate: A Review. Surveys in Geophysics, 35, 1175-1214. https://doi.org/10.1007/s10712-014-9284-0

Walsh, John E., \& Johnson, Claudia M. (1979) An analysis of arctic sea ice fluctuations.

Watkins, A. B., \& Simmonds, I. (1998) Current trends in Antarctic sea ice: the 1990s impact on a short climatology. Journal of Climate, 13(24), 4441-4451. https://doi.org/10.1175/15200442(2000)013<4441:CTIASI>2.0.CO;2

White, W., Peterson, R. (1996) An Antarctic circumpolar wave in surface pressure, wind, temperature and sea-ice extent. Nature, 380(6576):699-702. https://doi.org/10.1038/380699a0

Wouters, B., Martin-Espanol, A., Helm, V., Flament, T., Van Wessem, J. M., \& Ligtenberg, S. R. M., et al. (2015) Dynamic thinning of glaciers on the southern Antarctic peninsula. Science, 348(6237), 899-903. https://doi.org/10.1126/science.aaa5727

Wu, Y., \& Smith, K. L. (2016) Response of northern hemisphere midlatitude circulation to arctic amplification in a simple atmospheric general circulation model. Journal of Climate, 29(6), 160118113317003. https://doi.org/10.1175/JCLI-D-15-0602.1

Xue, F., Guo, P. \& Yu, Z. (2003) Influence of Interannual Variability of Antarctic Sea-Ice on Summer Rainfall in Eastern China. Advances in Atmospheric Sciences, 20, 97-102. https://doi.org/10.1007/BF03342053

Yang, X. (1992). Climatic effect of Antarctic sea ice in the northern hemisphere summer: a numerical experiment. Chinese Journal of Atmospheric Sciences.

Yuan, X., \& Martinson, D. G. (2001) The Antarctic dipole and its predictability. Geophysical Research Letters, 28(18), 3609-3612. https://doi.org/10.1029/2001GL012969

Zhang G. J., Mcfarlane N. (1995) Sensitivity of climate simulations to the parameterization of cumulus convection in the Canadian climate centre general circulation model. Atmosphere, 33(3):407-446. https://doi.org/10.1080/07055900.1995.9649539

Zhang, J., Lindsay, R., Schweiger, A., \& Steele, M. (2013) The impact of an intense summer cyclone on 2012 Arctic sea ice retreat. Geophysical Research Letters, 40(4), 720-726. https://doi.org/10.1002/grl.50190 
912 Zhu, Y. (2009) The Antarctic oscillation-East Asian summer monsoon connections in NCEP-1

913 and ERA-40. Adv. Advances in Atmospheric Sciences. 26, 707-716.

914 https://doi.org/10.1007/s00376-009-8196-2

915 Zwally, H. J., Comiso, J. C., Parkinson, C. L., Cavalieri, D. J., \& Gloersen, P. (2002) Variability

916 of Antarctic sea ice 1979-1998. Journal of Geophysical Research Oceans, 107(C5).

917 https://doi.org/10.1029/2000JC000733 

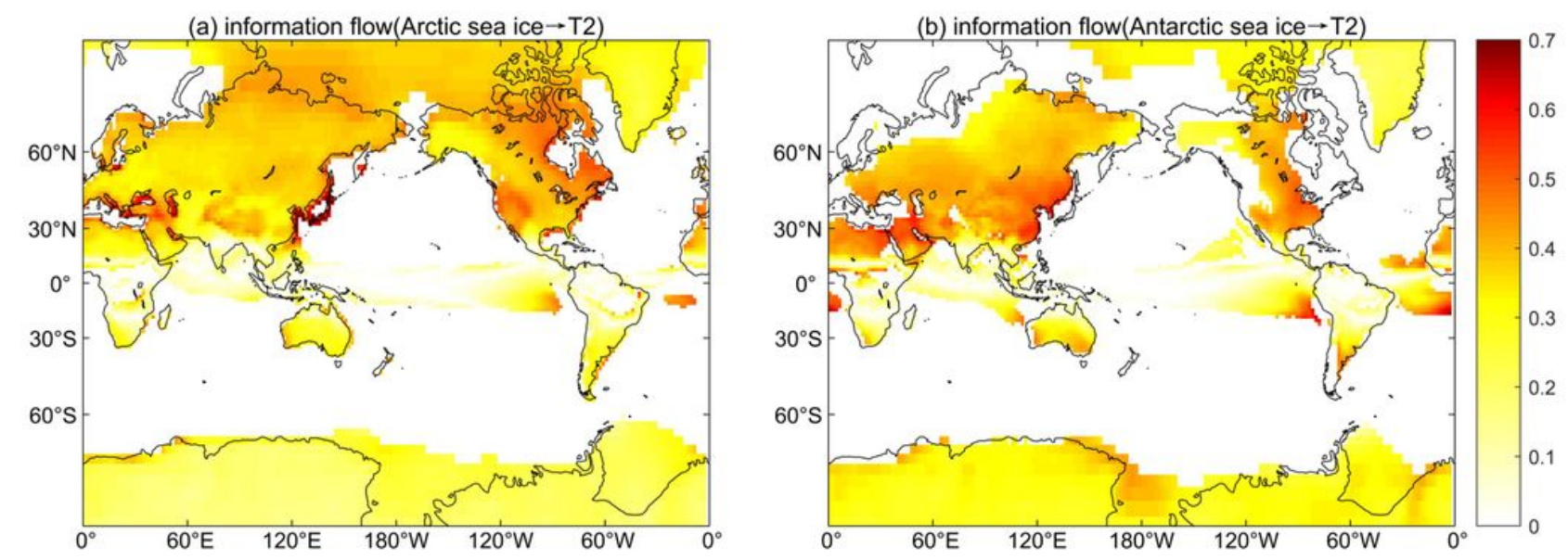

\section{Figure 1}

Spatial distribution of information flow from (a) Arctic sea ice (b) Antarctic sea ice to the $2 \mathrm{~m}$ temperature (filling; unit: nats/month). All shading areas exceed 95\% significance level. Note: The designations employed and the presentation of the material on this map do not imply the expression of any opinion whatsoever on the part of Research Square concerning the legal status of any country, territory, city or area or of its authorities, or concerning the delimitation of its frontiers or boundaries. This map has been provided by the authors.

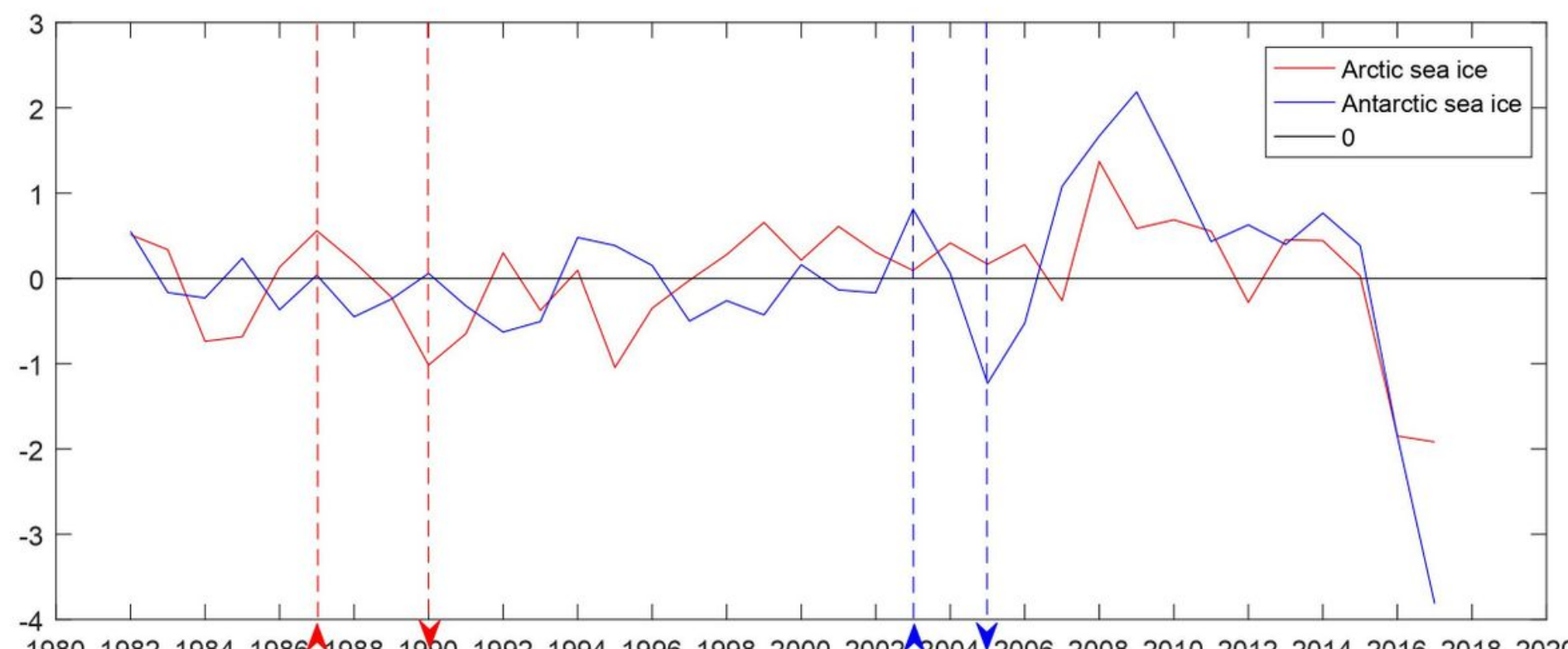

Figure 2 
Line chart of changes in Arctic and Antarctic sea ice relative to the average (the index has been standardized and detrended; red line: Antarctic sea ice; blue line: Arctic sea ice; unit: fraction; the red up/down arrow: Arctic sea ice increases/decreases abnormally; the blue up/down arrow: Antarctic sea ice increases/decreases abnormally)

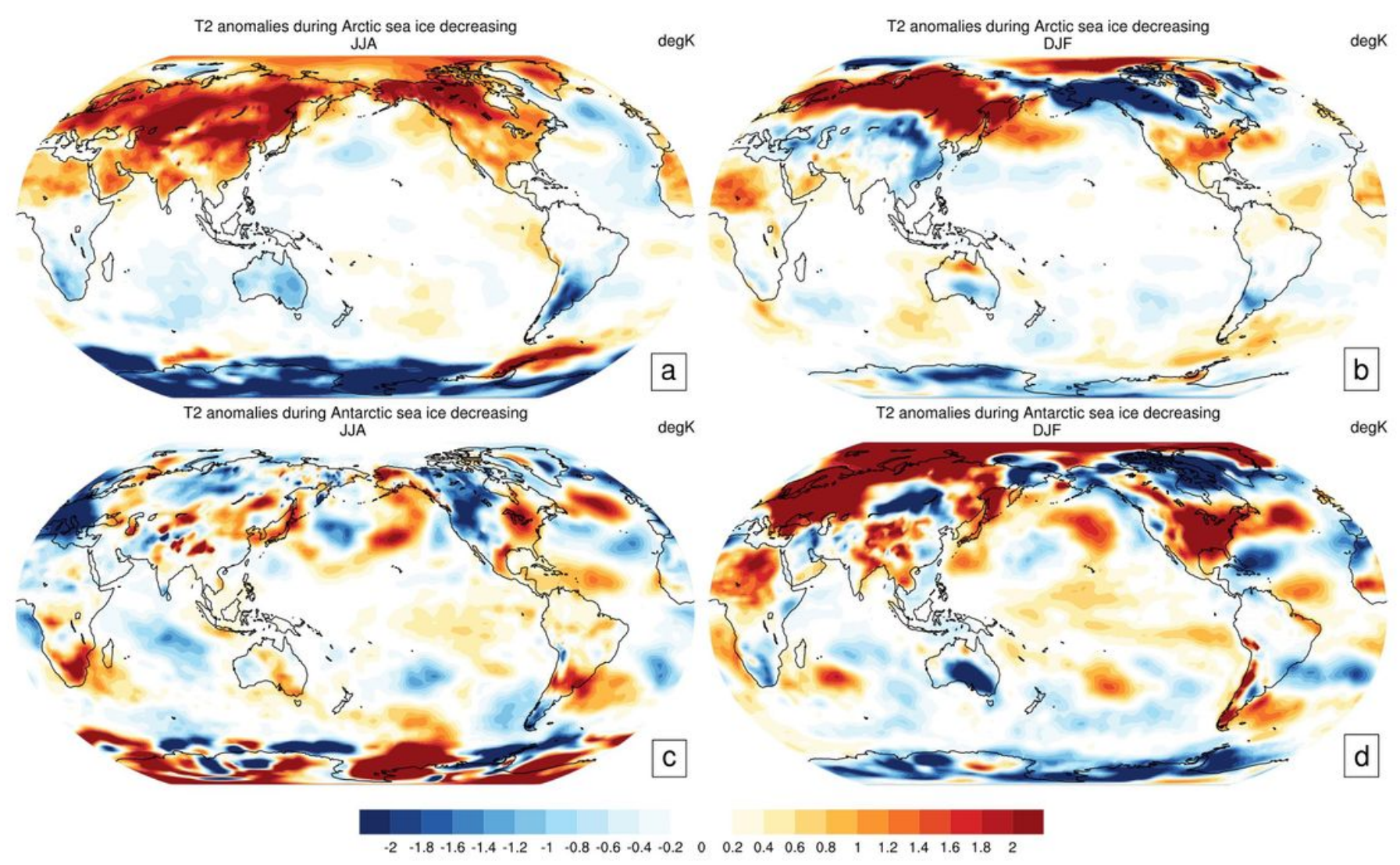

\section{Figure 3}

Spatial distributions of temperature changes different between the decrease anomalous years and the increase anomaly years of sea ice. T2 anomalies during Arctic sea ice decreasing in (a) summer average (b) winter average; T2 anomalies during Antarctic sea ice decreasing in (c) summer average (d) winter average (filling; unit: K). Note: The designations employed and the presentation of the material on this map do not imply the expression of any opinion whatsoever on the part of Research Square concerning the legal status of any country, territory, city or area or of its authorities, or concerning the delimitation of its frontiers or boundaries. This map has been provided by the authors. 


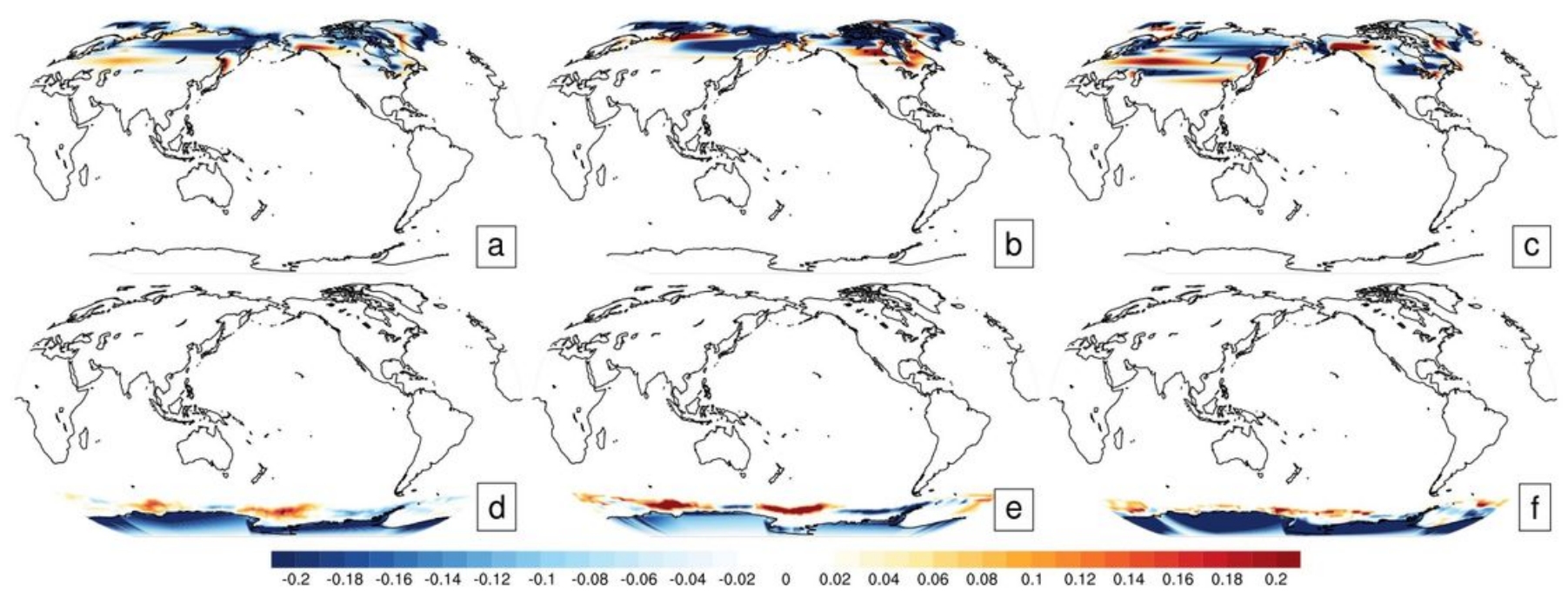

Figure 4

Changes of ice cover forced field between control (year 2000) and contrast experiments (year 1965). Spatial distribution of Arctic ice cover change: (a) annual average (b) summer average (c) winter average; Spatial distribution of Antarctic ice cover change: (d) annual average (e) summer average (f) winter average (filling, unit: fraction). Note: The designations employed and the presentation of the material on this map do not imply the expression of any opinion whatsoever on the part of Research Square concerning the legal status of any country, territory, city or area or of its authorities, or concerning the delimitation of its frontiers or boundaries. This map has been provided by the authors. 


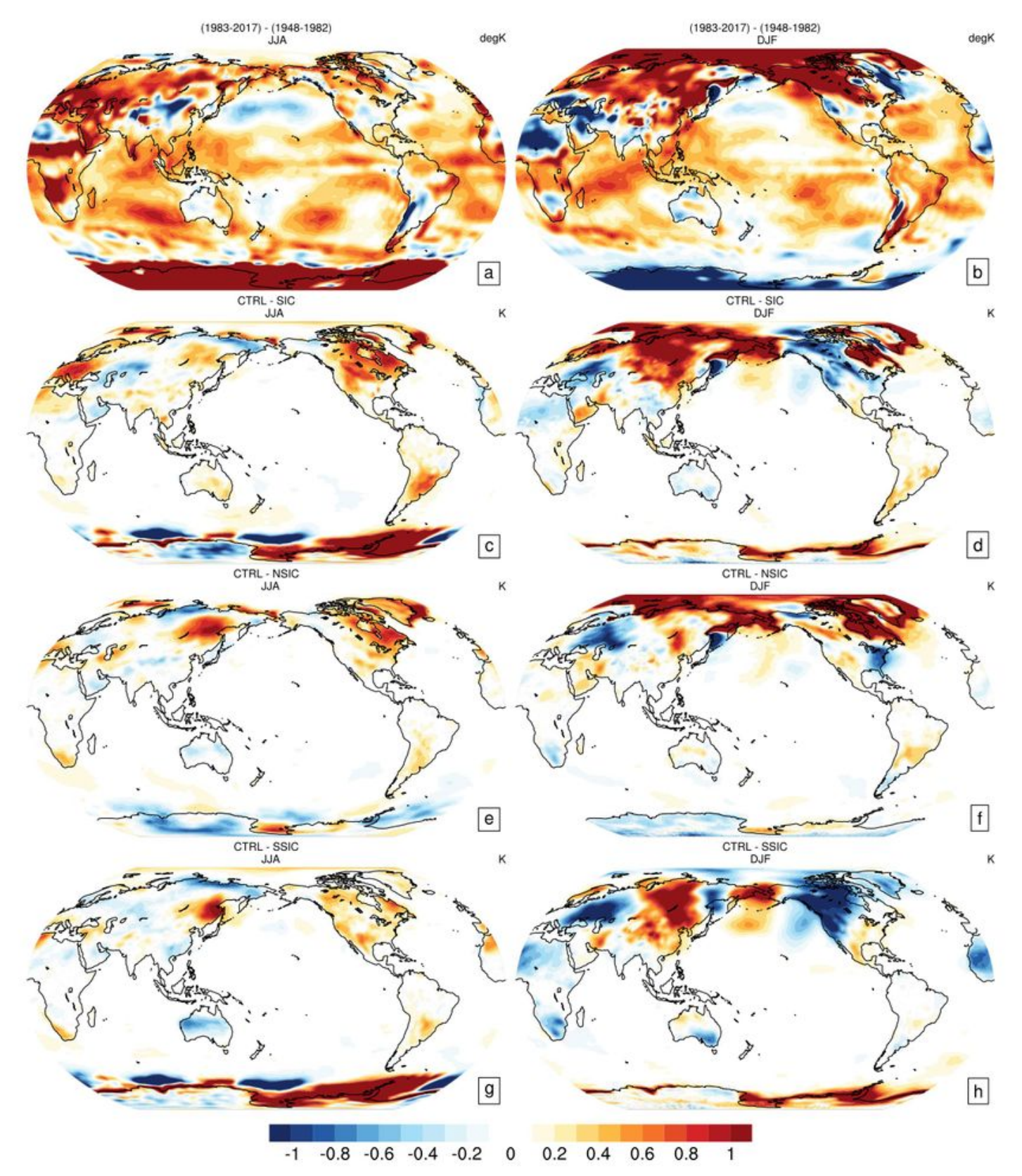

\section{Figure 5}

2m temperature. Difference between (a-b) 1983-2017 and 1948-1982. Difference between control and contrast experiments. (c-d) SIC, (e-f) NSIC, (g-h) SSIC (filling, unit: K; left column: annual average, right column: winter average). All shading areas exceed $95 \%$ significance level. Note: The designations employed and the presentation of the material on this map do not imply the expression of any opinion whatsoever on the part of Research Square concerning the legal status of any country, territory, city or 
area or of its authorities, or concerning the delimitation of its frontiers or boundaries. This map has been provided by the authors.

\section{Baroclinic eddy growth rate}
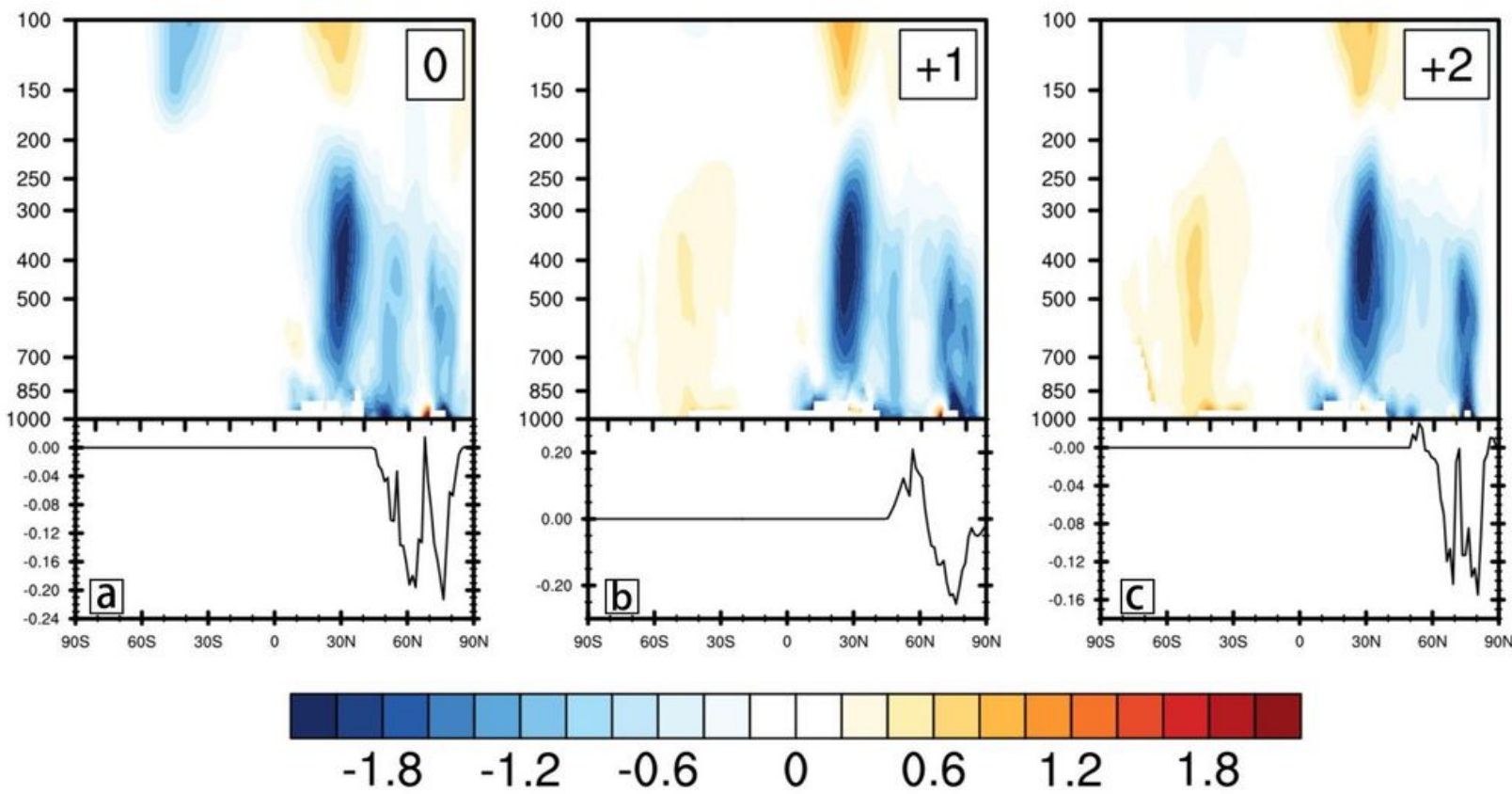

Wave-activity flux
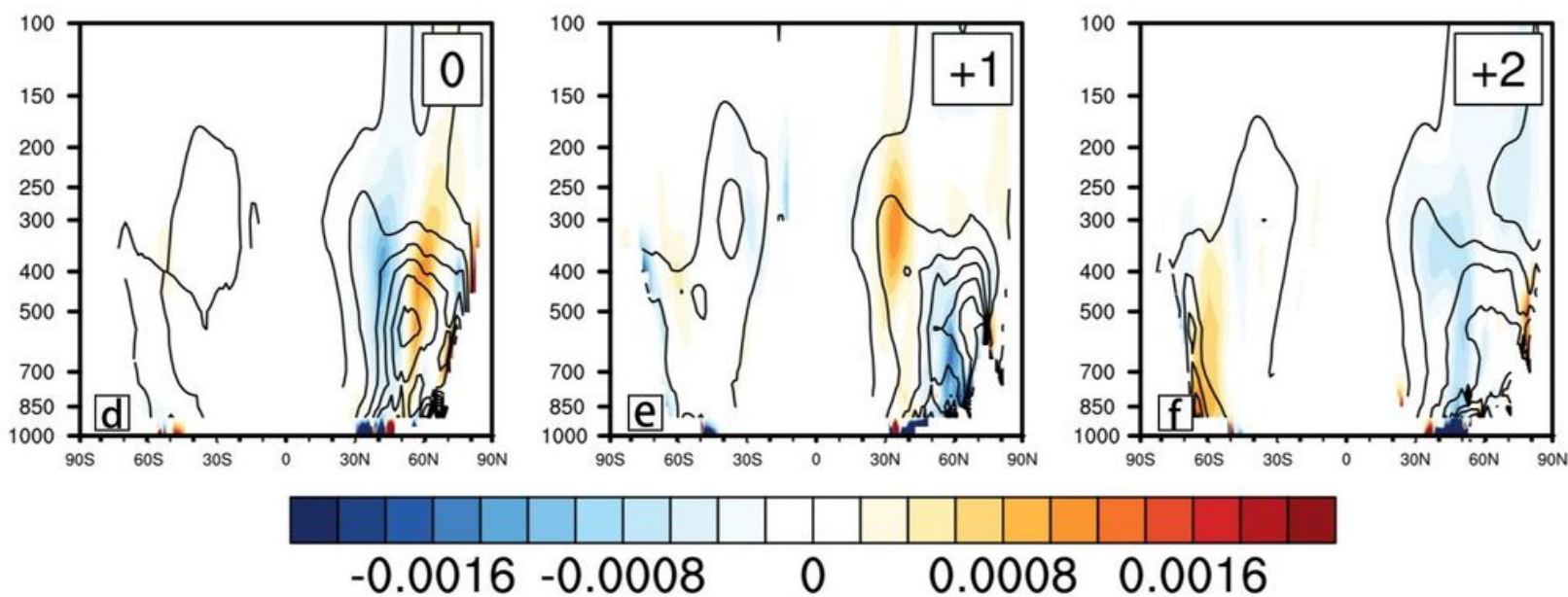

\section{Figure 6}

Vertical section of the difference in meridional mean (a-c) baroclinic growth rate and changes in Arctic ice cover (d-f) wave-activity flux between CTRL and NSIC, changes in Arctic ice cover in the forced field by month (filling, contour line: wave-activity flux distribution in CTRL, polyline: ice cover change with latitude, superscript: month). All shading areas exceed $95 \%$ significance level. 


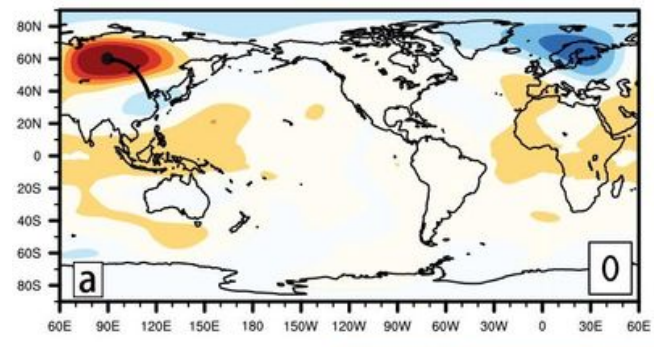

\begin{tabular}{ll}
\hline & 0.2 \\
\hline & -0.15
\end{tabular}

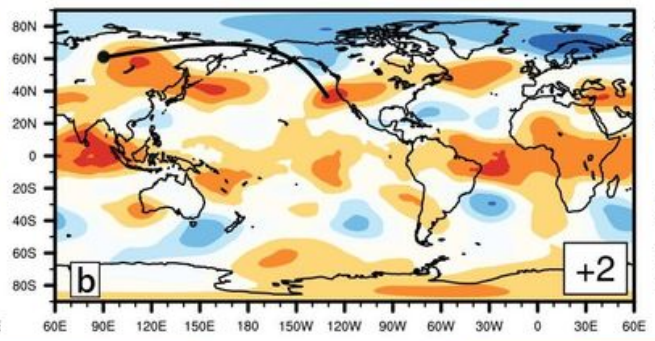

$-0.1$

$-0.05$
0

0.05

0.1

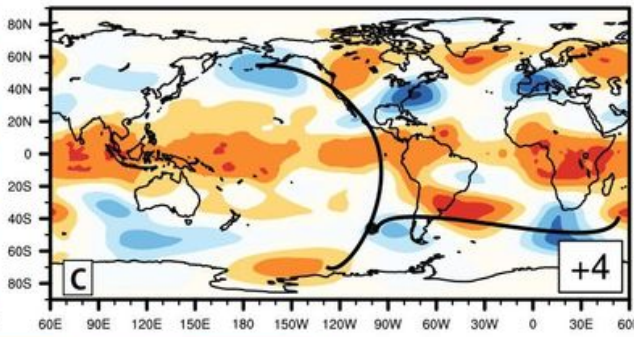

0.15

0.2

\section{Figure 7}

Lead-lag correlation coefficients between the 300-hPa height anomaly at the basepoint $\left(60^{\circ} \mathrm{N}, 90^{\circ} \mathrm{E}\right)$ and the global field (filling, black dot: the base point and branch point, subscript: month, black curves indicate the wave propagation path). All shading areas exceed $95 \%$ significance level. Note: The designations employed and the presentation of the material on this map do not imply the expression of any opinion whatsoever on the part of Research Square concerning the legal status of any country, territory, city or area or of its authorities, or concerning the delimitation of its frontiers or boundaries. This map has been provided by the authors. 
Baroclinic eddy growth rate
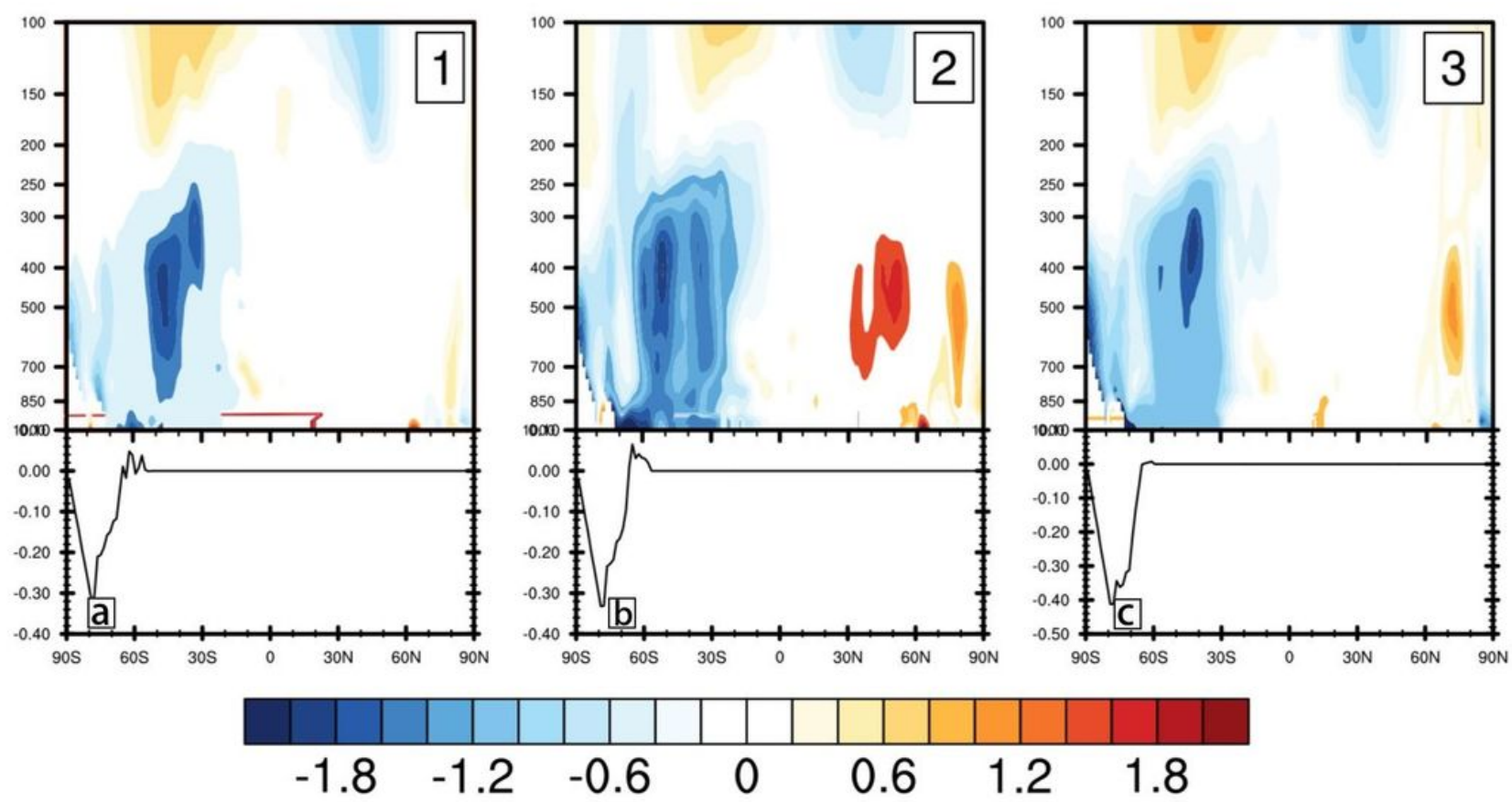

\section{Wave-activity flux}
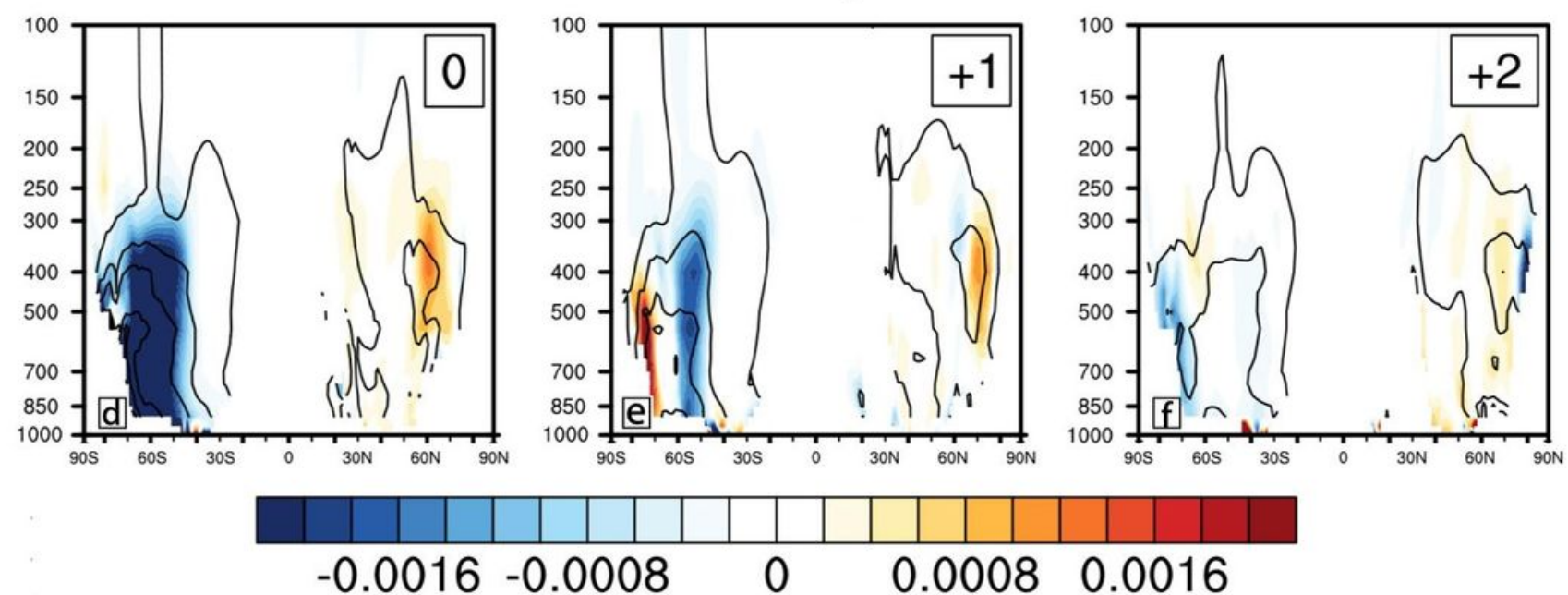

\section{Figure 8}

Vertical section of the difference in meridional mean (a-c) baroclinic growth rate and changes in Antarctic ice cover (d-f) wave-activity flux between CTRL and SSIC (filling, contour line: wave-activity flux distribution in CTRL, polyline: ice cover change with latitude, superscript: month). All shading areas exceed $95 \%$ significance level. 

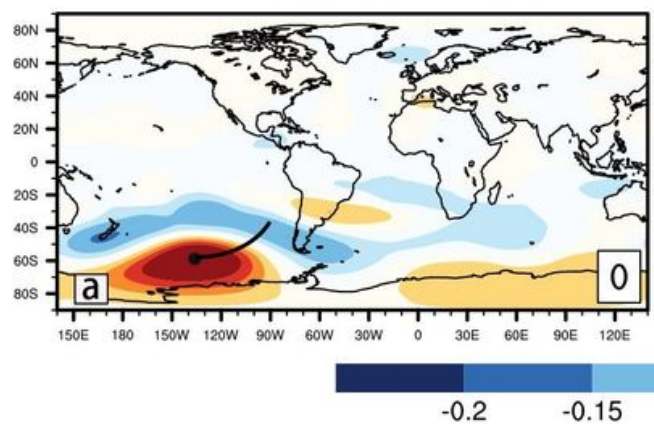

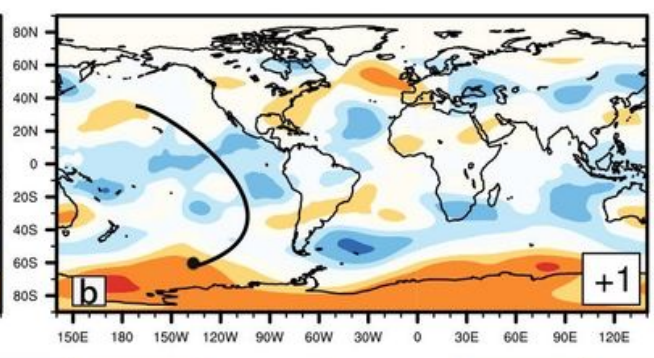

$-0$.

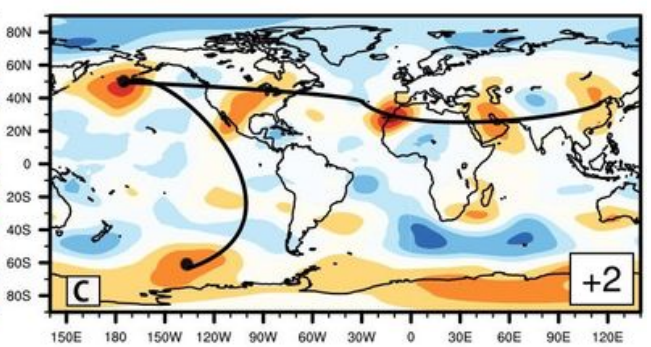

0.15

\section{Figure 9}

Lead-lag correlation coefficients between the 300 -hPa height anomaly at the basepoint $\left(60^{\circ} \mathrm{S}, 135^{\circ} \mathrm{W}\right)$ and the global field (filling, black dot: the base point and branch point, subscript: month, black curves indicate the wave propagation path) All shading areas exceed $95 \%$ significance level. Note: The designations employed and the presentation of the material on this map do not imply the expression of any opinion whatsoever on the part of Research Square concerning the legal status of any country, territory, city or area or of its authorities, or concerning the delimitation of its frontiers or boundaries. This map has been provided by the authors. 


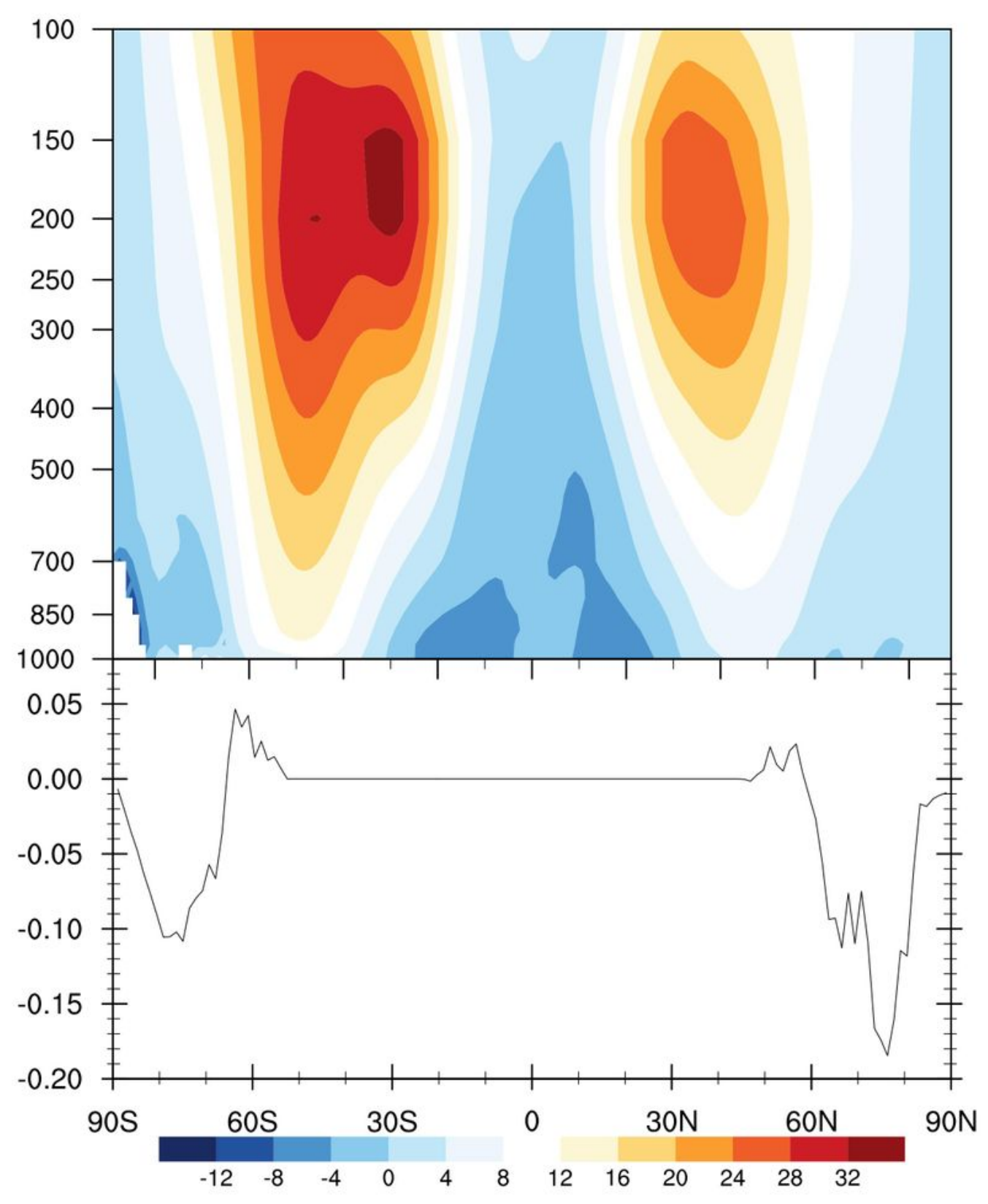

Figure 10

Vertical section of the zonal wind (filling, unit: $\mathrm{m} / \mathrm{s}$ ) and the line chart of ice coverage changes between the year 1965 and 2000 (polyline, unit: fraction). 


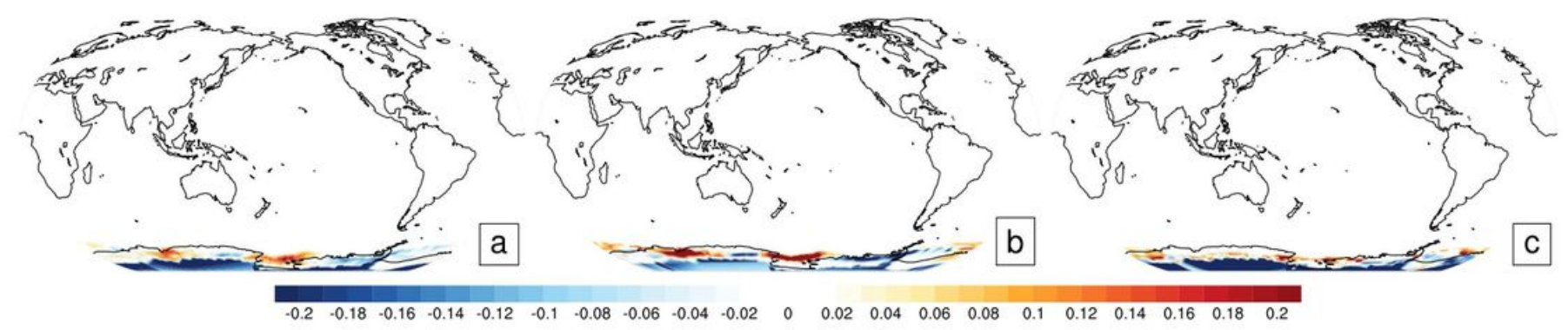

\section{Figure 11}

Change in ice cover forced field between control and SSIC_South_Movement experiments. (a: annual average, b: summer average, c: winter average; filling, unit: fraction) Note: The designations employed and the presentation of the material on this map do not imply the expression of any opinion whatsoever on the part of Research Square concerning the legal status of any country, territory, city or area or of its authorities, or concerning the delimitation of its frontiers or boundaries. This map has been provided by the authors. 


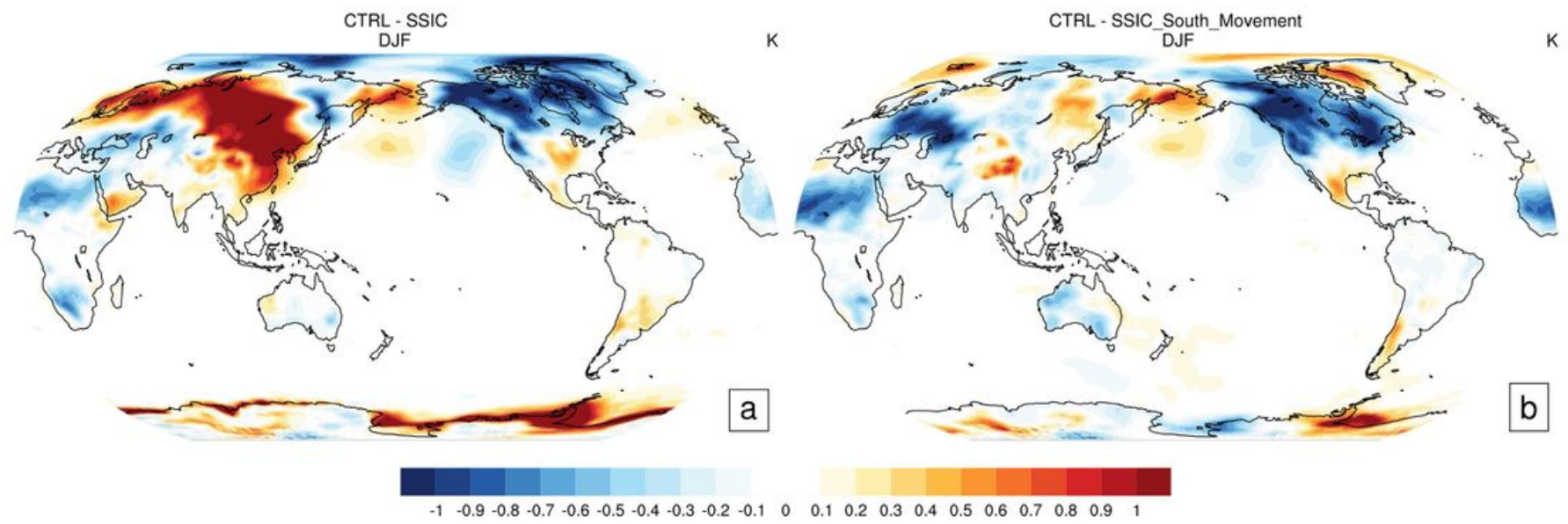

\section{Figure 12}

$2 \mathrm{~m}$ temperature anomalies. Difference between control and contrast experiments. (filling, unit: K; a: SSIC, b: SSIC_South_Movement). All shading areas exceed 95\% significance level. Note: The designations employed and the presentation of the material on this map do not imply the expression of any opinion whatsoever on the part of Research Square concerning the legal status of any country, territory, city or area or of its authorities, or concerning the delimitation of its frontiers or boundaries. This map has been provided by the authors. 


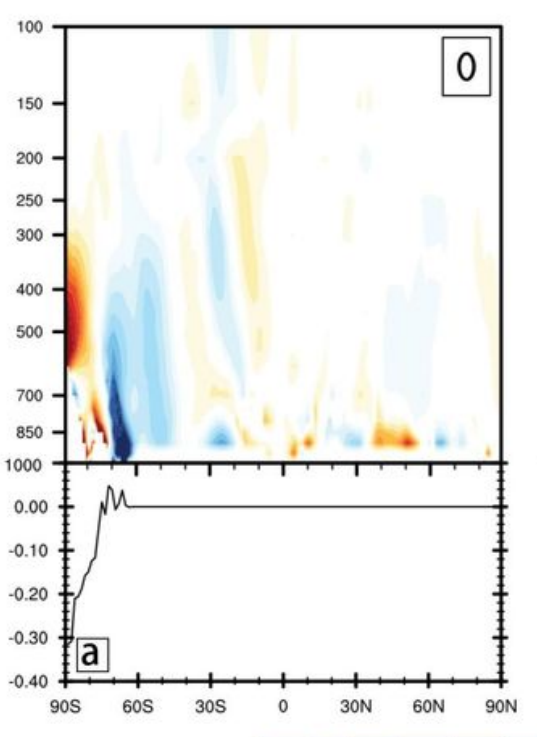

Baroclinic eddy growth rate
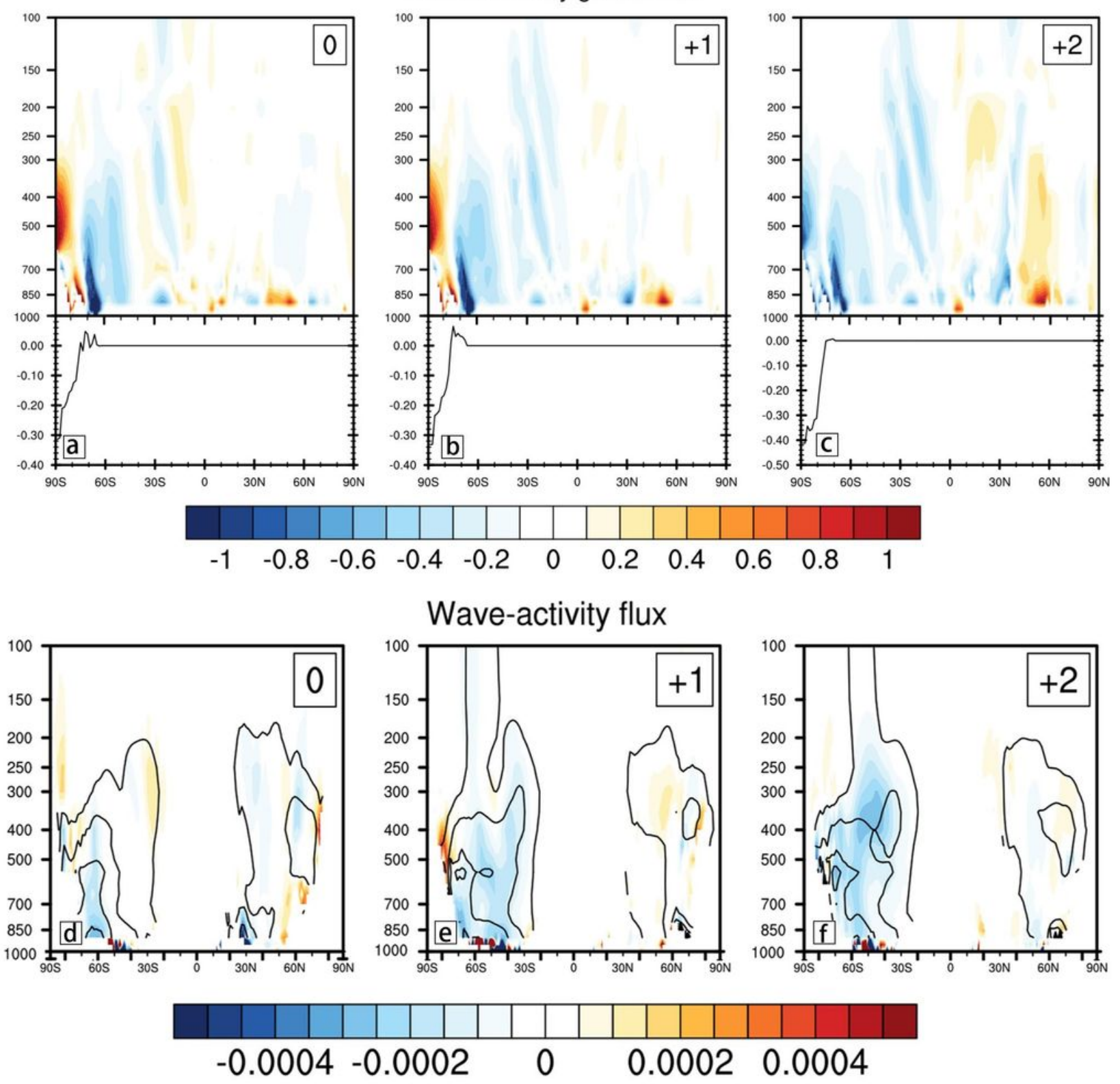

\section{Figure 13}

Vertical section of the difference in meridional mean baroclinic growth rate and wave-activity flux between SSIC and SSIC_South_Movement, changes in Antarctic ice cover in the forced field by month (filling, contour line: wave-activity flux distribution in SSIC, polyline: sea ice change with latitude, superscript: month). All shading areas exceed $95 \%$ significance level. 

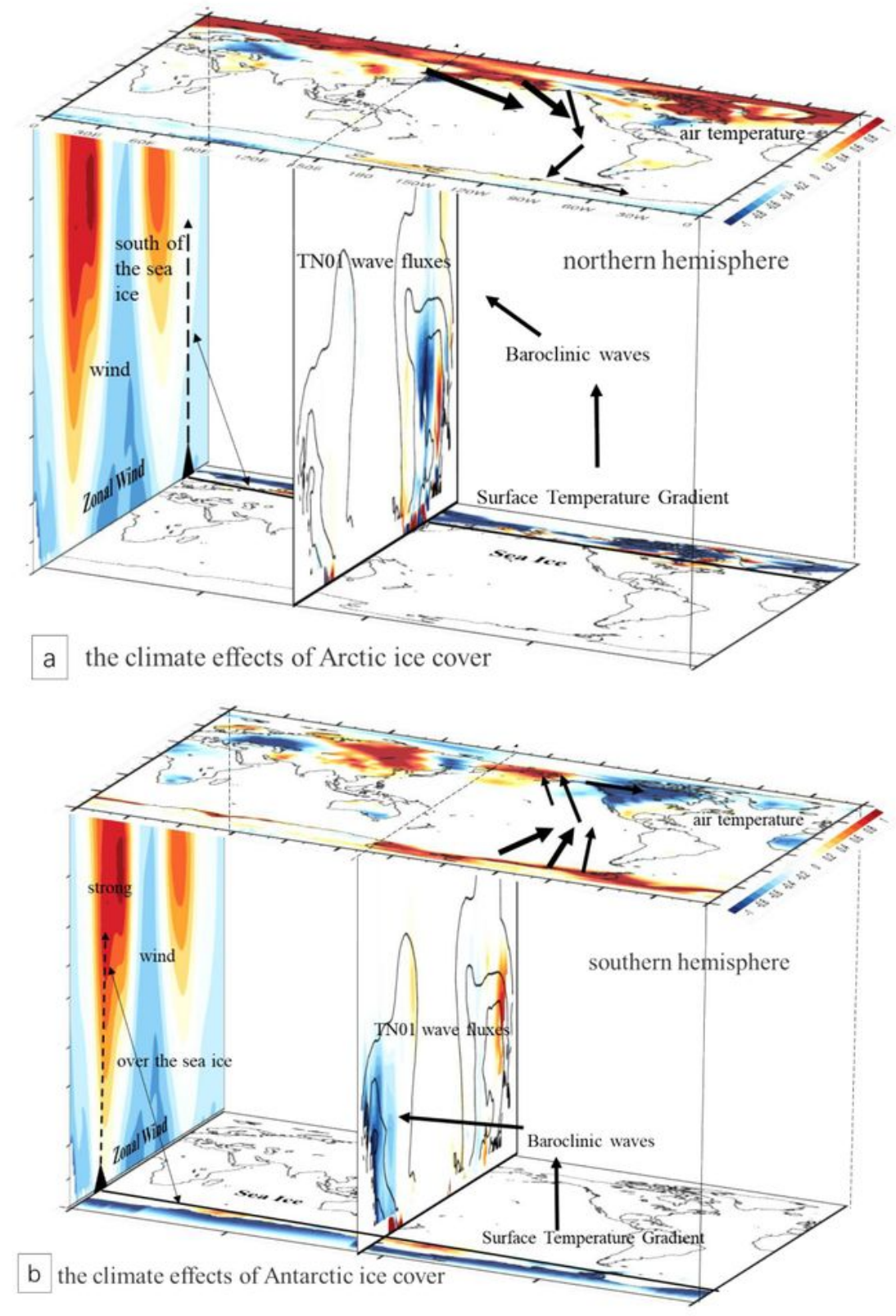

Figure 14

The conceptual map of the climate effects of ice cover (a) Arctic ice cover (b) Antarctic ice cover 